\title{
Genome-based selection and application of food-grade microbes for chickpea milk fermentation towards increased L-lysine content, elimination of indigestible sugars, and improved flavour
}

\author{
Muzi Tangyu' ${ }^{1}$, Michel Fritz' ${ }^{1}$ Rosa Aragao-Börner ${ }^{2}$, Lijuan Ye², Biljana Bogicevic ${ }^{2}$, Christoph J. Bolten ${ }^{3}$ and
} Christoph Wittmann ${ }^{1 *}$ (1)

\begin{abstract}
Background: Plant-based milk alternatives are more popular than ever, and chickpea-based milks are among the most commercially relevant products. Unfortunately, limited nutritional value because of low levels of the essential amino acid L-lysine, low digestibility and unpleasant taste are challenges that must be addressed to improve product quality and meet consumer expectations.

Results: Using in-silico screening and food safety classifications, 31 strains were selected as potential L-lysine producers from approximately 2,500 potential candidates. Beneficially, 30\% of the isolates significantly accumulated amino acids (up to $1.4 \mathrm{mM}$ ) during chickpea milk fermentation, increasing the natural level by up to $43 \%$. The bestperforming strains, B. amyloliquefaciens NCC 156 and L. paracasei subsp. paracasei NCC 2511, were tested further. De novo lysine biosynthesis was demonstrated in both strains by ${ }^{13} \mathrm{C}$ metabolic pathway analysis. Spiking small amounts of citrate into the fermentation significantly activated L-lysine biosynthesis in NCC 156 and stimulated growth. Both microbes revealed additional benefits in eliminating indigestible sugars such as stachyose and raffinose and converting off-flavour aldehydes into the corresponding alcohols and acids with fruity and sweet notes.
\end{abstract}

Conclusions: B. amyloliquefaciens NCC 156 and L. paracasei subsp. paracasei NCC 2511 emerged as multi-benefit microbes for chickpea milk fermentation with strong potential for industrial processing of the plant material. Given the high number of L-lysine-producing isolates identified in silico, this concept appears promising to support strain selection for food fermentation.

Keywords: L-lysine, Lactic acid bacteria, Lacticaseibacillus paracasei, Bacillus amyloliquefaciens, ${ }^{13} \mathrm{C}$ isotope study, Chickpea, Plant-based milk alternative, Plant milk, fermentation, Flavour, Indigestible sugar, Raffinose, Stachyose

*Correspondence: christoph.wittmann@uni-saarland.de

${ }^{1}$ Institute of Systems Biotechnology, Saarland University, Saarbrücken, Germany

Full list of author information is available at the end of the article

\section{Background}

Plant-based milk alternatives are growing in popularity. They offer attractive properties for consumers by being ecologically more sustainable and animal-welfare-friendly than dairy milks, lactose-free, and vegan. Notably, the world market for such products is continuously increasing

(C) The Author(s) 2021. This article is licensed under a Creative Commons Attribution 4.0 International License, which permits use, sharing, adaptation, distribution and reproduction in any medium or format, as long as you give appropriate credit to the original author(s) and the source, provide a link to the Creative Commons licence, and indicate if changes were made. The images or other third party material in this article are included in the article's Creative Commons licence, unless indicated otherwise in a credit line to the material. If material is not included in the article's Creative Commons licence and your intended use is not permitted by statutory regulation or exceeds the permitted use, you will need to obtain permission directly from the copyright holder. To view a copy of this licence, visit http://creativeco mmons.org/licenses/by/4.0/. The Creative Commons Public Domain Dedication waiver (http://creativecommons.org/publicdomain/ zero/1.0/) applies to the data made available in this article, unless otherwise stated in a credit line to the data. 
and is expected to surpass US $\$ 26$ billion by 2023 [1]. As prominent example, chickpea (Cicer arietinum L.), one of the oldest and most widely consumed legumes worldwide [2], is regarded an attractive source of milk-alternative consumer products $[3,4]$ with good protein quality $[5,6]$.

Unfortunately, suspensions of chickpea flour (termed chickpea milk below due to their milk-like appearance) do not match animal milk in all desired characteristics, which is a limitation that is generally observed for plantbased milk alternatives [7]. This limitation also holds for the essential amino acid L-lysine, which is required for hormone formation, catalytic and structural proteins, and immune system support and is therefore one of the most impacting nutrients [8]. Critically, it exhibits much lower abundance in chickpea-based milk than in animal milk, approximately half of the amount in a typical $10 \%$ dry matter formulation $[9,10])$. Moreover, chickpea milk contains elevated levels of indigestible sugars such as raffinose and stachyose, which cause flatulence, diarrhoea, and other discomfort upon consumption [11]. In addition, it exhibits a grassy and beany taste that does not meet consumer expectations [12].

Microbial fermentation is a well-established way to improve the nutritional quality of plant-based milk alternatives [1]. For example, fermentation of milks from peanut, soy, cowpea, and mung bean increased protein quality and digestibility and occasionally also the L-lysine content [1319]. Admittedly, only selected microbial strains improve desired features [20]. For example, natural microbes rarely overproduce L-lysine [21].

Here, we present a systematic workflow to fortify a chickpea milk using fermentation with natural food-grade microbes. To improve upon the low level of L-lysine, more than 30 strains were selected as candidates based on their genomic repertoire related to L-lysine metabolism (Fig. 1). A screening round revealed that one-third (9) of the tested strains significantly accumulated L-lysine during chickpea milk fermentation. ${ }^{13} \mathrm{C}$ isotope studies showed that the two best-performing strains, Lacticaseibacillus paracasei subsp. paracasei Nestlé Culture Collection (NCC) 2511 and Bacillus amyloliquefaciens NCC 156, synthetize L-lysine de novo. Both microbes were used for a more detailed investigation of the fermentation process. They beneficially altered the amino acid and protein profile, utilized (indigestible) carbohydrates, and formed desired flavour molecules, which highlights them as microbes well suited for chickpea milk fermentation.

\section{Results}

Genome-based selection of food-grade microbes for L-lysine production

Bacterial genomes of the NCC were analysed for their features related to L-lysine, including L-lysine biosynthesis,
L-lysine degradation, and pathways competing with L-lysine biosynthesis for carbon precursors (Fig. 1). A component from the pathway architecture for bacterial L-lysine biosynthesis, the lys $A$ gene (encoding diaminopimelate decarboxylase) was inferred as a premium selection criterion to identify potential L-lysine producers. This enzyme catalyses the terminal step of L-lysine synthesis, downstream of meso-diaminopimelate, where all synthetic routes converge (Fig. 1). Therefore, the presence of $l y s A$ was an essential (minimal) feature required for L-lysine formation. In total, 2472 bacterial NCC genomes contained an annotated lys $A$ gene, and most of them belonged to the orders Lactobacillales, Bacillales, Bifidobacteriales, and Corynebacteriales. Fewer than half of the genomes $(1,117)$ additionally included a dapF gene, potentially indicating the succinylase and/or acetylase route to synthesize L-lysine (Fig. 1). Only 14 strains contained the $d d h$ gene (encoding diaminopimelate dehydrogenase) as a key step of the dehydrogenase pathway.

The selection was narrowed down by considering only strains approved for use in the food and feed chain according to the European Food Safety Authority [22]. Among all potential L-lysine producers, i. e. all strains that contained lysA plus either $d a p \mathrm{~F}$ or $d d h, 945$ strains exhibited the qualified presumption of safety (QPS) status and therefore fulfilled this extra requirement. They belonged to five different families (Lactobacillaceae, Bacillaceae, Bifidobacteriaceae, Corynebacteraceae, Carnobacteriaceae), including 12 genera and 33 different species. None of the strains that contained a $d d h$ gene met the food safety constraint. Carnobacterium and Pediococcus were not further considered because they are mainly associated with producing bacteriocins for food preservation [23, 24], and the fermentation of materials other than milk such as wine, cheese, sausage, and cabbage [25], leaving Lactobacillaceae (757), Bacillaceae (34), Bifidobacteriaceae (119), and Corynebacteraceae (2) for the final selection. Accordingly, 31 potential producers (all containing lys $A$ and $d a p F$ that covered the identified taxonomic diversity were selected for experimental studies. The selected strains represented 10 genera and 19 different species (Additional file 1: Table S1): (i) Lactobacillus helveticus (3), Lactobacillus johnsonii (3), Lactobacillus acidophilus (1), Lactobacillus delbrueckii (1), Limosilactobacillus reuteri (3), Limosilactobacillus pontis (1), Lacticaseibacillus paracasei (2), Lactiplantibacillus plantarum (1), Fructilactobacillus sanfranciscensis (3), Levilactobacillus brevis (1), Lentilactobacillus hilgardii (1); (ii) Bifidobacterium longum (1) and Bifidobacterium infantis (1); (iii) Bacillus amyloliquefaciens (2), Bacillus flexus (2), Bacillus licheniformis (1), Bacillus pumilus (1), and Bacillus subtilis (1); and (iv) Corynebacterium stationis (2). In addition, Lactobacillus jensenii NCC 2867, 


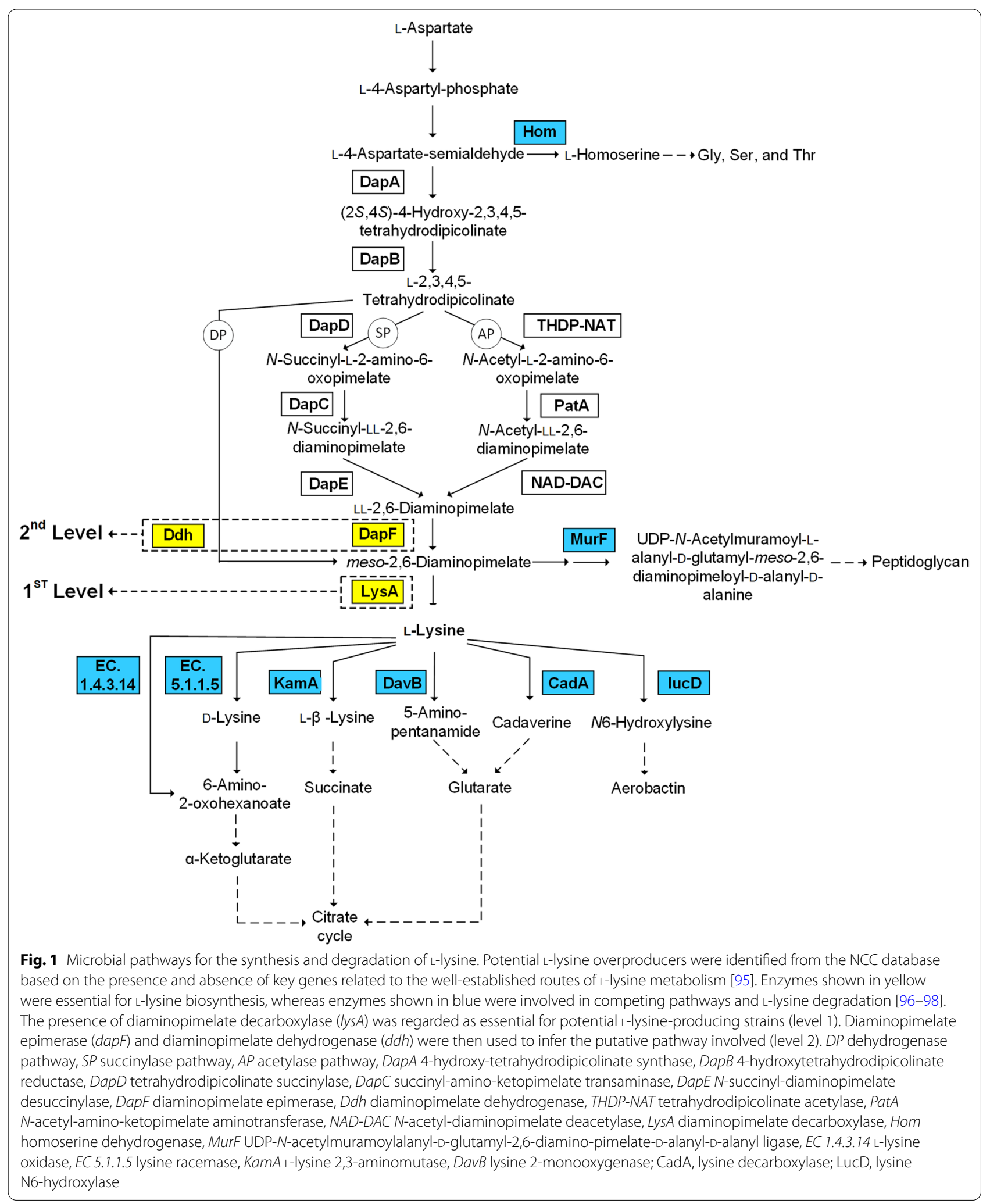


lacking $l y s A$, was used as a negative control. Regarding oxygen sensitivity, the selected strains were classified as obligate anaerobes (6), aerotolerant (17), and obligate aerobes (9).

\section{Nutritional characteristics of chickpea milk}

Initial tests revealed that a one-step pre-treatment was not suitable to provide homogeneous, sterile chickpea milk for fermentation. Standard autoclaving $\left(121{ }^{\circ} \mathrm{C}\right.$, $15 \mathrm{~min}$ ) resulted in undesired starch gelation and an inhomogeneous suspension, while pasteurization $\left(63{ }^{\circ} \mathrm{C}\right.$, $5 \mathrm{~h}$ ) failed to avoid contamination in the subsequent fermentation studies (Additional file 1: Fig. S1). After several tests, a two-step heat pre-treatment was developed. It consisted of an initial phase of heating and stirring $\left(75^{\circ} \mathrm{C}, 2 \mathrm{~h}\right)$, followed by autoclaving $\left(121^{\circ} \mathrm{C}, 15 \mathrm{~min}\right)$. Notably, this treatment fully avoided starch gelation. Furthermore, it provided a sterile, homogenous, and easy to process suspension (Additional file 1: Fig. S1).

From a chemical composition viewpoint, the unfiltered chickpea milk contained $16.2 \%$ (w/w, dry mass) protein, $8.7 \%$ soluble carbohydrates, $7.4 \%$ fat, $2.5 \%$ organic acid, and a remaining fraction accounting for $65.2 \%$ (e.g., starch, fibres, ash, and salt) (Fig. 2) which well compared to previous studies, given seasonal and geographical fluctuations $[3,6,9,26,27]$. Among the nonessential amino acids, L-glutamate $(3.3 \%)$ and L-aspartate $(1.6 \%)$ were most abundant. The major essential amino acids were L-leucine (1.4\%) and L-phenylalanine (1.0\%). As expected, the level of L-lysine $\left(8.7 \mathrm{mg}\right.$ ( $\mathrm{g}$ dry mass) ${ }^{-1}$ ) was only $30-70 \%$ of the value observed for animal milk [28]. Soluble carbohydrates comprised digestible (sucrose, maltose) and indigestible carbohydrates (raffinose, stachyose, verbascose). Stachyose (3.0\%, w/w, dry mass), sucrose $(2.8 \%)$, raffinose $(1.4 \%)$, and maltose $(1.2 \%)$ were the major soluble sugars. Verbascose was present in lower amounts, whereas the levels of glucose and fructose were negligible. In addition, chickpea milk contained organic acids such as $1.3 \% \alpha$-ketoglutarate ( $\mathrm{w} / \mathrm{w}$, dry mass), $1.2 \%$ citrate, and trace amounts of succinate.

\section{Evaluation of the pre-selected microbes for chickpea milk fermentation}

The selected 31 strains differed in their genomic repertoire regarding the number of completely and partially annotated L-lysine biosynthetic pathways (Fig. 3). They were next experimentally evaluated for their capability to ferment chickpea milk, and L. jensenii was included as a negative control (Fig. 3). Generally, the established fermentation process was highly reproducible, which enabled a clear evaluation of strain performance. In total, $60 \%$ of the strains (19 out of 32 ) were able to grow (Additional file 1: Table S2). Depending on species and strain, the observed increase in the number of living cells ranged

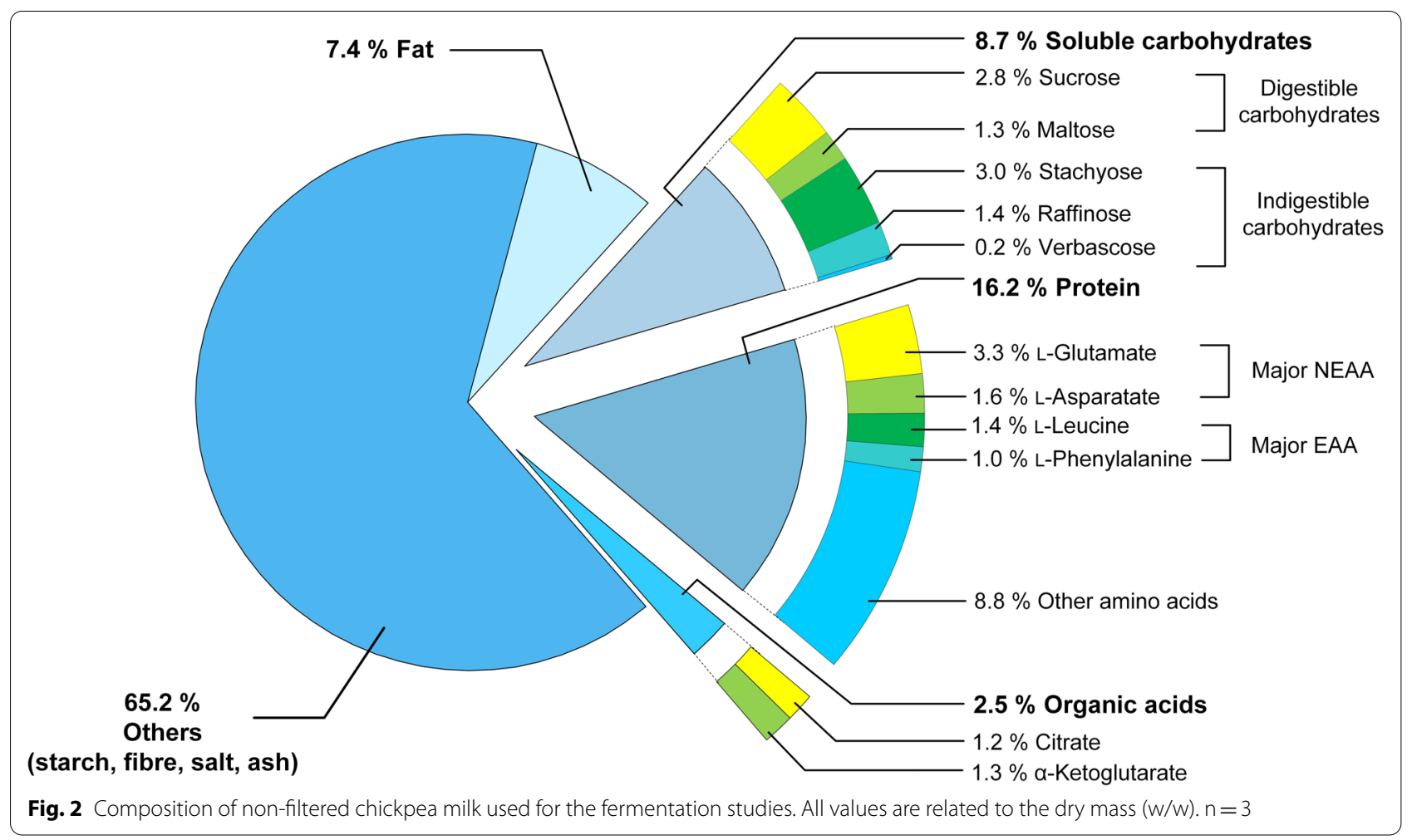




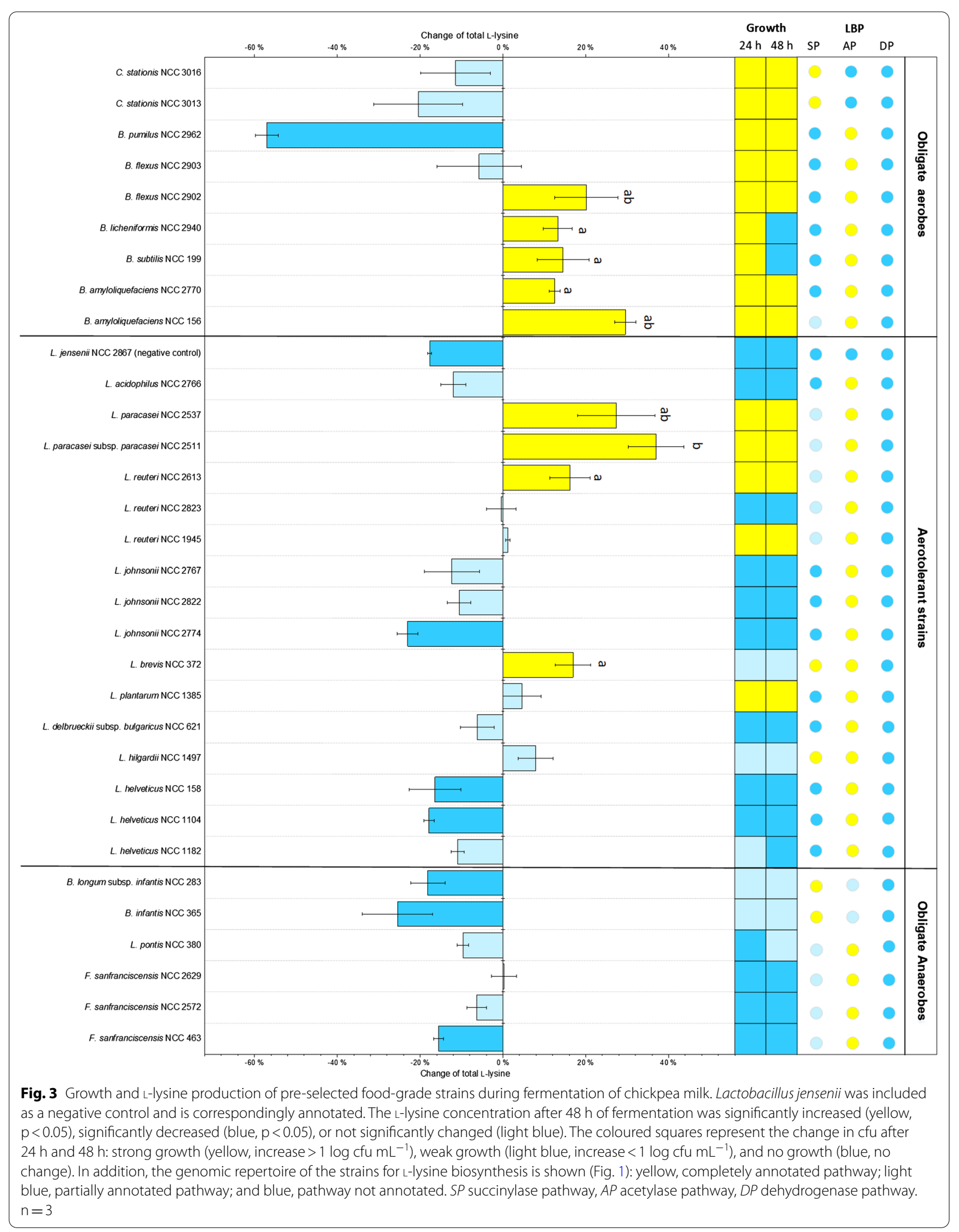


from 0.2 to $3.2 \log \mathrm{cfu} \mathrm{mL}^{-1}$. Generally, obligate aerobic and aerotolerant strains grew well, while obligate anaerobes showed weak or even no growth. The bacilli and corynebacteria showed the strongest growth. The cfu numbers for these strains increased at least tenfold (1 $\log$ ) while the bifidobacteria grew only weakly. For the lactobacilli, the outcome was mixed. Some strains grew well (L. plantarum, L. paracasei subsp. paracasei and two out of three $L$. reuteri), while others (F. sanfranciscensis, $L$. helveticus, L. johnsonii, $L$. acidophilus, the remaining $L$. reuteri and the negative control strain $L$. jensenii) did not grow.

Notably, 30\% of the strains ( 9 out of 31 potential producers) increased the level of L-lysine. The producers were exclusively found among four genera: Lacticaseibacillus, Limosilactobacillus, Levilactobacillus, and Bacillus. High and low producers were equally distributed between lactic acid bacteria and Bacillus groups. The best, third best, fifth best, and sixth best producers were lactic acid bacteria strains (L. paracasei subsp. paracasei NCC 2511, L. paracasei NCC 2537, L. reuteri NCC 2613 and L. brevis NCC 372), while the second, fourth, seventh, eighth and ninth highest L-lysine levels were achieved by Bacillus strains (B. amyloliquefaciens NCC 156, B. flexus NCC 2902, B. flexus NCC 2940, B. subtilis NCC 199, B. licheniformis NCC 2940, B. amyloliquefaciens NCC 2770). L. paracasei subsp. paracasei NCC 2511 and B. amyloliquefaciens NCC 156 increased the L-lysine content by $37 \%$ and $30 \%$, respectively. In contrast, none of the Bifidobacterium and Corynebacterium isolates increased the L-lysine level. Several isolates degraded L-lysine. B. pumilus NCC 2962 decreased the $\mathrm{L}$-lysine content by over $50 \%$. Fifteen strains did not alter the content significantly.

L. paracasei subsp. paracasei NCC 2511 and B. amyloliquefaciens NCC 156 appeared most promising for further studies regarding their superior capability to overproduce L-lysine. The inspection of their genomes revealed that they possessed a rich repertoire to potentially improve also other important traits of the plant milk. They contained several genes, functionally assigned to catalyse flavour formation, such as alcohol dehydrogenase [29], aldehyde dehydrogenase [29], and enzymes of branched chain amino acid metabolism [30] (Additional file 1: Table S3). Moreover, genes encoding carbohydrate degrading enzymes, known to be involved in the removal of indigestible sugars [31], were present. Therefore, both strains were subjected to a more-detailed characterization.

\section{Fermentation of chickpea milk using B. amyloliquefaciens NCC 156}

The physiology of B. amyloliquefaciens NCC 156 during chickpea milk fermentation was monitored over a period of $48 \mathrm{~h}$ (Fig. 4). The microbe went through several distinct phases of an obviously altered metabolism. The initial phase was the main phase of growth. The cells immediately started to proliferate, and the cfu number increased almost 1000 -fold during the first $8 \mathrm{~h}$. Notably, the initial phase $(0-16 \mathrm{~h})$ was also the major phase of $\mathrm{L}$-lysine production $(42.8 \%$ increase), which appeared growth coupled. TCA cycle-related intermediates (citrate, $\alpha$-ketoglutarate) were utilized as major substrates during this initial phase. Carbohydrates were also taken up but at only a rather low rate. Dissolved oxygen was quickly consumed and became limiting after approximately $10 \mathrm{~h}$, while the $\mathrm{pH}$ value significantly dropped. Acetate was the only by-product formed in significant amounts. Then, growth and L-lysine accumulation slowed (16-30 h). Likely linked to limited oxygen availability, fermentation products such as lactate and 2,3-butanediol emerged. With depletion of citrate and $\alpha$-ketoglutarate, NCC 156 switched to consume mainly sucrose, while raffinose and stachyose degradation continued. After approximately $30 \mathrm{~h}$, sucrose was used up, triggering an accelerated use of stachyose and raffinose (30-48 h). The level of maltose, on the other hand, increased. Overall, B. amyloliquefaciens NCC 156 showed an outstanding capability to degrade indigestible carbohydrates. Stachyose (94.8\%) and raffinose (88.6\%) were almost completely consumed.

Remarkably, the formed L-lysine was largely present as a free amino acid. The extracellular L-lysine level increased almost ninefold to a final value of $1.4 \mathrm{mM}$ after $24 \mathrm{~h}$ of fermentation. The $\mathrm{pH}$ value increased towards the end and finally again reached the starting value of approximately 6 . At the end of the fermentation, acetate $(40 \mathrm{mM})$, acetoin $(30 \mathrm{mM}), 2,3$-butanediol $(19 \mathrm{mM})$, and maltose $(11 \mathrm{mM})$ were the main products. Ethanol, isobutyrate, and isovalerate, often fermentation products for other strains of Bacillus, were not detected. Regarding essential amino acids, the microbe increased the total levels of L-phenylalanine (18.6\%), L-valine (11.1\%), and

(See figure on next page.)

Fig. 4 Time-resolved fermentation of chickpea milk using B. amyloliquefaciens NCC 156 (left, A-G) and L. paracasei subsp. paracasei NCC 2511 (right, $\mathbf{H}-\mathbf{N})$. The data comprise living cell number ( $(\mathrm{fu})(\mathbf{A}, \mathbf{H})$, dissolved oxygen level and $\mathrm{pH}$ value (B, I), and the concentrations of total $L-l y s i n e ~(\mathbf{C}, \mathbf{J})$, sucrose, maltose $(\mathbf{D}, \mathbf{K})$, raffinose, stachyose $(\mathbf{E}, \mathbf{L})$, citrate, a-ketoglutarate, succinate $(\mathbf{F}, \mathbf{M})$, acetate, acetoin, 2,3-butanediol, lactate, and pyruvate $(\mathbf{G}$, N). $n=3$ 


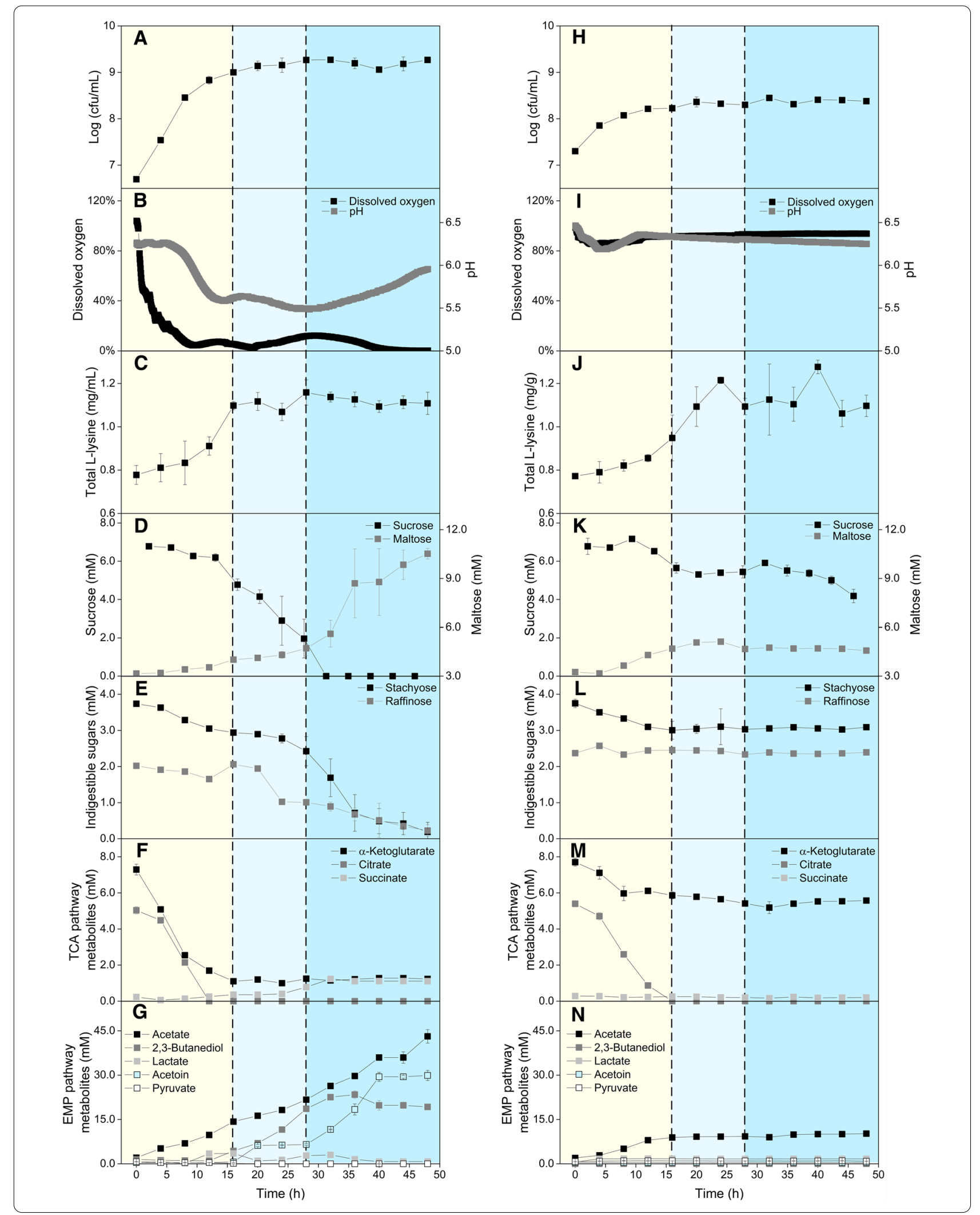




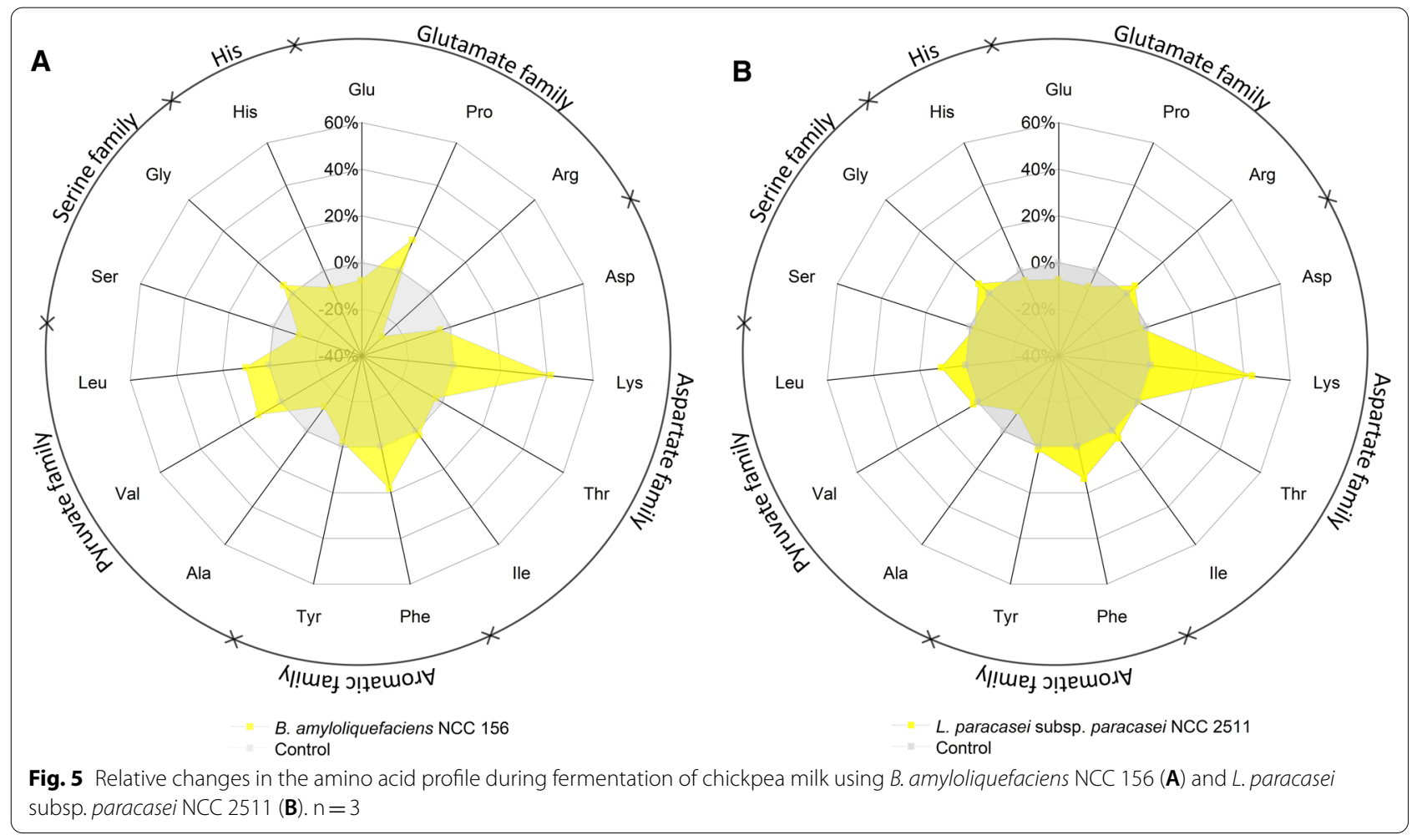

L-leucine (10.0\%) in addition to L-lysine, while the nonessential amino acids L-glutamate/L-glutamine, L-alanine, L-serine, and L-arginine - all fuelling the EMP pathway and the TCA cycle, respectively-were degraded (Fig. 5).

\section{Fermentation of chickpea milk using L. paracasei subsp. paracasei NCC 2511}

L. paracasei subsp. paracasei NCC 2511 showed a completely different fermentation behaviour than $B$. amyloliquefaciens NCC 156 (Fig. 4). Its growth was much weaker, and changes in $\mathrm{pH}$ and dissolved oxygen were also less pronounced. Citrate was the preferred carbon source. It was completely depleted during the first hours, together with some of the $\alpha$-ketoglutarate (18.2\%). Sucrose (38.3\%) and stachyose (16.2\%) were partially consumed, while the raffinose level did not change, indicating a weaker ability of $L$. paracasei subsp. paracasei $\mathrm{NCC}$ 2511 to ferment carbohydrates. Acetate $(10 \mathrm{mM})$ and lactate $(2 \mathrm{mM})$ accumulated as by-products during the initial phase. Considering the generally lower metabolic activity, the high increase in total L-lysine (45.7\%) during the first $24 \mathrm{~h}$ was remarkable for this strain. Interestingly, the formed L-lysine remained inside the cells and/or protein bound because the level of the free amino acid did not change significantly (data not shown). L. paracasei subsp. paracasei NCC 2511 slightly changed the amino acid profile (Fig. 5). The levels of L-phenylalanine (14.0\%) and L-leucine $(11.0 \%)$ increased, while L-glutamate/Lglutamine and L-alanine were partially consumed.

\section{Impact of fermentation on flavour development}

GC-MS-based analysis revealed a strong impact of fermentation on the abundance of flavour-related volatiles (Fig. 6). In total, 30 volatiles were identified in unfermented and fermented chickpea milk, including various saturated and unsaturated organic alcohols, aldehydes, ketones, organic acids, lactones, and furans. In unfermented chickpea milk, volatiles with grassy and beany flavours, such as hexanal, pentanal, 1-octen-3-ol, trans2-octenal, and 2-pentyl-furan, dominated, while sweet and fruity aroma compounds (e.g., 2-heptanone, octanal, and $\gamma$-heptyl-butyrolactone) were present in only low amounts. Fermentation with $B$. amyloliquefaciens and $L$. paracasei subsp. paracasei changed the flavour profile significantly, whereby each microbe yielded a unique signature at the end of the fermentation (Fig. 7). L. paracasei subsp. paracasei NCC 2511 produced various alcohols, such as 2-ethyl-1-hexanol, 1-pentanol, 1-hexanol, 1-heptanol, 1-octanol, 1-nonanol, and 2-phenyethanol. B. amyloliquefaciens generated mainly organic acids, including isobutyric acid, 2-methyl-butanoic acid, and 2-methyl-hexanoic acid. Aldehydes such as pentanal, hexanal, heptanal, and trans-2-octanal were eliminated by both strains, whereas 2-pentyl-furan was at 
least partially removed. B. amyloliquefaciens further consumed 2-heptanone and benzaldehyde. The unfermented control was largely unchanged, except for a certain degree of evaporation of some of the more volatile compounds, underlining the contribution of the microbes to the change in flavour compounds.

\section{Metabolic pathway analysis: L-Lysine biosynthesis}

It appeared interesting to study the L-lysine pathway in more detail. As inferred from the genomic repertoire, it contained L-aspartate as central intermediate (Fig. 1). Monitoring of the incorporation of ${ }^{13} \mathrm{C}$ from $\left[{ }^{13} \mathrm{C}_{4}\right]$ $\mathrm{L}$-aspartate, added as a tracer substrate to the fermentation process, into L-lysine was used to elucidate biosynthesis in vivo. For this purpose, $11 \mathrm{mM}\left[{ }^{13} \mathrm{C}_{4}\right] \mathrm{L}$-aspartate was added to medium. After $20 \mathrm{~h}$ of fermentation, the ${ }^{13} \mathrm{C}$ enrichment of total L-lysine was analysed by $\mathrm{GC} /$ MS. In a control study, the medium was supplemented with the same amount of naturally labelled $\mathrm{L}$-aspartate, and the ${ }^{13} \mathrm{C}$ enrichment of total L-lysine was analysed. The ${ }^{13} \mathrm{C}$ enrichment of total L-lysine in the control was $1.1 \pm 0.1 \%$, reflecting the expected natural ${ }^{13} \mathrm{C}$ abundance [32]. Notably, it was significantly increased to a value of $1.9 \pm 0.0 \%$ in the tracer study $(\mathrm{p}<0.01)$ which indicated that $\left[{ }^{13} \mathrm{C}_{4}\right] \mathrm{L}$-aspartate had been converted into $\mathrm{L}$-lysine (Fig. 8). The ${ }^{13} \mathrm{C}$ enrichment of extracellular L-lysine was even more increased $(5.6 \pm 0.1 \%)$, underlining that cells excreted large amounts of the free amino acid, formed from L-aspartate, into the media (Fig. 8). Parallel analysis of the ${ }^{13} \mathrm{C}$ enrichment of $\mathrm{L}$-aspartate revealed a substantial decrease from a high initial value of $38.5 \pm 1.2 \%$ $(0 \mathrm{~h})$ to $2.7 \pm 0.1 \%(20 \mathrm{~h})$ indicating that the tracer was largely used up during this time (Fig. 8). In a parallel study, de novo biosynthesis of L-lysine was also observed for $L$. paracasei subsp. paracasei NCC 2511 . Using $\left[{ }^{13} \mathrm{C}_{4}\right]$ $\mathrm{L}$-aspartate as tracer, the ${ }^{13} \mathrm{C}$ enrichment of total $\mathrm{L}$-lysine after $20 \mathrm{~h}$ was again significantly increased $(1.4 \pm 0.0 \%$, $\mathrm{p}<0.01$ ) (Fig. 8). On a first glance, it appeared less pronounced. The weaker increase in ${ }^{13} \mathrm{C}$ enrichment in L-lysine than in NCC 156, however, partially resulted from the fact that the added $\left[{ }^{13} \mathrm{C}_{4}\right] \mathrm{L}$-aspartate was only slightly used, i. e. the ${ }^{13} \mathrm{C}$ enrichment of total L-aspartate after $20 \mathrm{~h}(36.5 \pm 0.4 \%)$ was almost as high as the starting value $(38.5 \pm 1.2 \%)$ indicating only little consumption (Fig. 8).

As shown above, citrate appeared to be the preferred carbon source of both strains, and, for B. amyloliquefaciens, its consumption happened simultaneously with L-lysine formation, suggesting a potential link (Fig. 4). In additional studies, citrate $(10 \mathrm{mM})$ was spiked into the medium. For B. amyloliquefaciens NCC 156, this resulted in $27 \%$ increased L-lysine production to $1.8 \pm 0.2 \mathrm{mM}$ after $24 \mathrm{~h}$, while the growth of the microbe was stimu-

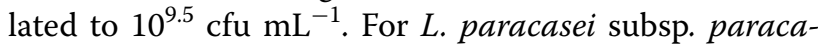
$s e i$, no significant impact on growth or L-lysine formation was observed (data not shown).

The genome of L. paracasei subsp. paracasei contained a potential citrate degradation route via citrate lyase, while that of B. amyloliquefaciens NCC 156 did not (Additional file 1: Table S4). The latter observation suggested that, in this microbe, citrate was apparently converted via the TCA cycle towards oxaloacetate and the precursor of L-lysine instead (Fig. 9).

\section{Metabolic pathway analysis: Fermentation by-products and flavour molecules}

The citrate supplemented cultures (see above) were now evaluated for citrate-related effects on formation of flavour molecules and fermentative by-products. Both microbes differed in the genomic repertoire regarding these parts of metabolism (Additional file 1: Table S4). Citrate contributed to the formation of different organic acids in $L$. paracasei subsp. paracasei, including acetate, lactate, pyruvate, and $\alpha$-ketoglutarate, when spiked into chickpea milk (Fig. 9AB). In addition, acetoin and 2,3-butanediol were obviously produced from citrate. $B$. amyloliquefaciens formed higher amounts of short-chain fatty acids (such as isovalerate and isobutyrate) from citrate.

In a series of further experiments, different chickpea milk contained aldehydes (Figs. 6, 7)-flavour compounds themselves and precursors for other flavours as well-were individually spiked into the cultures. Both microbes efficiently reduced pentanal, hexanal, heptanal, octanal, nonanal, and benzaldehyde into the corresponding alcohols (Fig. 9C). L. paracasei subsp. paracasei

(See figure on next page.)

Fig. 6 GC-MS-based analysis of volatile compounds in unfermented chickpea milk (A), chickpea milk fermented for $24 \mathrm{~h}$ with B. amyloliquefaciens NCC 156 (B) and chickpea milk fermented for $24 \mathrm{~h}$ with L. paracasei subsp. paracasei NCC 2511 (C). The peak numbers refer to the identified analytes: 1, acetone; 2, pentanal; 3, 1-pentanol; 4, hexanal; 5, 1-hexanol; 6, 2-heptanone; 7, heptanal; 8, cyclooctane; 9, benzaldehyde; 10, 1-octen-3-ol; 11, 2-pentylfuran, 12, octanal; 13, phenyl-methanol; 14, trans-2-octenal; 15, 1-nonanal; 16, ү-heptyl-butyrolactone; 17, acetoin; 18, isobutyric acid; 19, 2-methyl-hexanoic acid; 20, 2-methyl-butanoic acid; 21, acetoin acetate; 22, 1-heptanol; 23, ethyl-1-hexanol; 24, 1-octanol; 25, 2-nonanone; 26, maltol; 27, 2,3-butanedione; 28, 2-phenylethanol; 29, 1-nonanol; 30, nonanoic acid; $\mathrm{M}$, peaks from sample matrix and instrumental background noise 


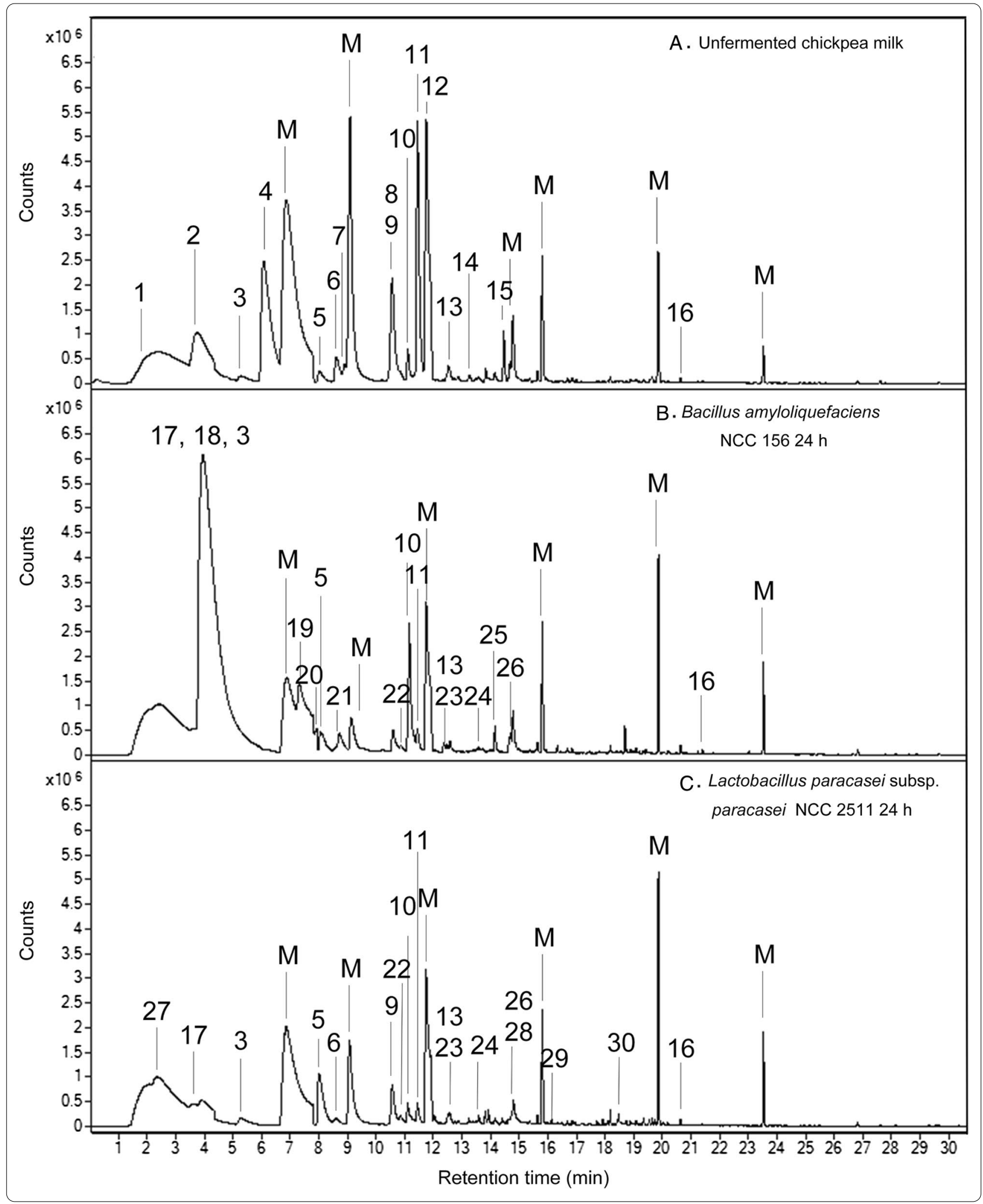




\begin{tabular}{|c|c|c|c|c|c|c|}
\hline \multirow[b]{2}{*}{ Compound } & \multirow[b]{2}{*}{$\begin{array}{l}\text { RT } \\
\text { (min) }\end{array}$} & \multirow[b]{2}{*}{ Flavor and odor properties ${ }^{a}$} & \multicolumn{4}{|c|}{ Abundance } \\
\hline & & & Control $0 \mathrm{~h}$ & Control $24 \mathrm{~h}$ & $\begin{array}{c}\text { Bacillus } \\
\text { amyloliquefaciens } \\
\text { NCC } 156\end{array}$ & $\begin{array}{c}\text { Lactobacillus } \\
\text { paracasei subsp. } \\
\text { paracasei } \\
\text { NCC 2511 } \\
\end{array}$ \\
\hline \multicolumn{7}{|l|}{ Favored volatiles } \\
\hline 2,3-Butanedione & 2.52 & Buttery ${ }^{A B}$, sweet ${ }^{B}$, creamy ${ }^{B}$ & & & & () \\
\hline Acetoin & 3.95 & Pleasant ${ }^{\mathrm{B}}$, buttery ${ }^{\mathrm{B}}$, creamy $^{\mathrm{BC}}$, sweet $^{\mathrm{D}}$, toasted $\mathrm{d}^{\mathrm{D}}$ & & & & O \\
\hline 1-Pentanol & 5.32 & Fermented ${ }^{B}$, balsamic ${ }^{E}$, alcoholic $F$ & 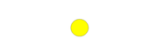 & 0 & 0 & O \\
\hline Acetoin acetic acid & 8.52 & Fruity $^{\mathrm{B}}$, creamy $^{\mathrm{B}}$, sweet $^{\mathrm{B}}$ & & & 0 & \\
\hline 2-Heptanone & 8.60 & Fruity ${ }^{G}$, fora $^{A}$, sweet $^{G}$ & 0 & - & & $\circ$ \\
\hline 1-Octanal & 11.76 & Fruity ${ }^{\mathrm{F}}$, citrus ${ }^{\mathrm{FG}}$, sweet ${ }^{\mathrm{H}}$ & 0 & - & & \\
\hline Phenylmethanol & 12.58 & Fruity ${ }^{\mathrm{B}}$, floral ${ }^{\mathrm{Bl}}$, sweet ${ }^{\mathrm{B}}$, honey ${ }^{\mathrm{C}}$ & ○ & - & 0 & - \\
\hline Maltol & 14.61 & Sweet $^{\mathrm{B}}$, caramellic $^{\mathrm{B}}$ & & - & 0 & 0 \\
\hline 1-Nonanol & 16.14 & Flora ${ }^{B}$, rose $^{C}$ & & & & ○ \\
\hline 2-Phenylethanol & 14.71 & Flora $^{\mathrm{B}}$, rose ${ }^{\mathrm{B}}$, sweet ${ }^{\mathrm{B}}$ & & & & - \\
\hline Y-Heptyl-butyrolactone & 20.62 & Fruity $^{B}$, creamy ${ }^{B}$ & - & - & - & - \\
\hline \multicolumn{7}{|l|}{ Neutral volatiles } \\
\hline Acetone & 1.93 & Fruity $^{\mathrm{B}}$, solvent ${ }^{\mathrm{B}}$, ethereal ${ }^{\mathrm{B}}$ & - & & & \\
\hline Isobutyric acid & 5.18 & Buttery $^{B}$, cheesy ${ }^{B}$, sour ${ }^{B}$, rancid ${ }^{B}$ & & & & \\
\hline 2-Methyl-hexanoic acid & 7.85 & Cheesy $^{B}$, fruity ${ }^{B}$, oily ${ }^{B}$, sour ${ }^{C}$ & & & & \\
\hline 2-Methyl-butanoic acid & 7.93 & Sour $^{B}$, cheesy ${ }^{B}$, dirty ${ }^{B}$, fermented ${ }^{B}$ & & & 0 & \\
\hline 1-Hexanol & 8.03 & Fruity $^{\mathrm{BE}}$, lemmon ${ }^{\mathrm{C}}$, herbaceous ${ }^{\mathrm{H}}$, nice green $\mathrm{EG}$ & 0 & 0 & 0 & 0 \\
\hline 1-Heptanal & 8.90 & Citrus $^{\mathrm{D}}$, fatty ${ }^{\mathrm{D}}$, flora $\mathrm{G}$, rancid $\mathrm{DF}$ & 0 & - & & \\
\hline Cyclooctane & 10.45 & Camphoraceous' & - & - & & \\
\hline Benzaldehyde & 10.52 & Nutty $^{H}$, bitter ${ }^{H}$, almond ${ }^{A C H}$, sweet ${ }^{C}$ & () & 0 & & 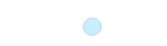 \\
\hline 2-Ethyl-1-hexanol & 12.48 & Citrus $^{B}$, fatty ${ }^{B}$, rose $^{D}$, green $^{D}$ & & & 0 & • \\
\hline 1-Octanol & 13.59 & Fruity ${ }^{H}$, flora ${ }^{H}$, waxy ${ }^{B}$, aldehyde ${ }^{B C}$ & & & - & - \\
\hline 2-Nonanone & 14.15 & Fruity ${ }^{G}$, flora ${ }^{H}$, green ${ }^{D}$, hot milk ${ }^{D}$, soap ${ }^{D}$ & & & - & \\
\hline 1-Nonanal & 14.46 & Fruity ${ }^{H}$, citrus ${ }^{\mathrm{CEFG}}$, flora $\mathrm{EFG}$, fatty ${ }^{\mathrm{G}}$, green $^{\mathrm{E}}$ & 0 & - & & \\
\hline Nonanoic acid & 18.46 & Sweet ${ }^{F}$, terpenic ${ }^{F}$, cinnamon ${ }^{F}$, cheesy ${ }^{B}$, waxy ${ }^{B}$ & & & & - \\
\hline \multicolumn{7}{|l|}{ Unfavored volatiles } \\
\hline 1-Pentanal & 3.74 & Green $F$, grassy ${ }^{F}$, nutty ${ }^{A G}$, woody ${ }^{H}$ & O & & & \\
\hline 1-Hexanal & 6.07 & Green ${ }^{F G H}$, grassy ${ }^{C D F H}$, nutty ${ }^{A}$, fat $^{D}$, oxidized oil ${ }^{J}$ & 0 & O & & \\
\hline 1-Heptanol & 10.86 & Green $^{G}$, mushroom $^{F}$, rancid $^{C}$ & & & - & - \\
\hline 1-Octen-3-ol & 11.11 & Mushroom ${ }^{A C F G H}$, fungiD & - & $\bullet$ & - & - \\
\hline 2-Pentyl-furan & 11.45 & Beany ${ }^{A C H}$, green $^{D}$, grassy ${ }^{\jmath}$, nutty ${ }^{A H}$ & 0 & 0 & - & - \\
\hline trans-2-Octenal & 13.24 & Green $^{\mathrm{D}}$, vegetable ${ }^{\mathrm{F}}$, nutty ${ }^{\mathrm{D}}$, fatty $\mathrm{D}$ & - & 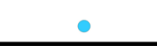 & & \\
\hline \multicolumn{7}{|c|}{$<2.5 \times 10^{6} \bigcirc 2.5 \times 10^{6}-5 \times 10^{7} \bigcirc 5 \times 10^{6}-2 \times 10^{7} \bigcirc 2 \times 10^{7}-1 \times 10^{8}$} \\
\hline $\begin{array}{l}\text { Fig. } 7 \text { Aroma developm } \\
\text { The data reflect changes } \\
\text { milk, incubated under the } \\
\text { based on their mass spec } \\
\text { classification into favoure } \\
\text { desired and undesired ar } \\
\text { (dark blue) relates to prev } \\
\text { previous studies and data }\end{array}$ & $\begin{array}{l}\text { during } \\
\text { the abur } \\
\text { ame con } \\
\text { using th } \\
\text { volatiles } \\
\text { ha prope } \\
\text { us studie } \\
\text { ases: } \mathbf{A}[1\end{array}$ & $\begin{array}{l}\text { ermentation of chickpea milk with L. paracasei su } \\
\text { dance of volatiles during } 24 \text { h of fermentation in } \\
\text { ditions (control). Volatile compound analysis was } \\
\text { e NIST library. The given abundance reflects the } \\
\text { vith flora, fruity, sweet, and creamy aroma proper } \\
\text { ties (light blue), and unfavoured volatiles potenti } \\
\text { s and databases on flavour [69, 99-101]. RT retent } \\
\text { 02], B [103], C [76], D [104], E [105], F [69], G [106], }\end{array}$ & $\begin{array}{l}\text { p. paracasei } N \\
\text { mparison to t } \\
\text { inducted usin } \\
\text { an peak areas } \\
\text { (yellow), ne } \\
\text { y contributing } \\
\text { n time. The as } \\
\text { [107], I [108], }\end{array}$ & $\begin{array}{l}C 2511 \text { and } B \text {. } \\
\text { heir abundance } \\
\mathrm{GC} / \mathrm{MS} \text {, and } \mathrm{C} \\
\text { from triplicate } \\
\text { tral volatiles w } \\
\text { to the beany, } \\
\text { igned flavour } \\
\text { [109]. } \mathrm{n}=3\end{array}$ & $\begin{array}{l}\text { amyloliquefacie } \\
\text { e in non-fermen } \\
\text { compounds wer } \\
\text { experiments. C } \\
\text { vith concentratio } \\
\text { green, and mush } \\
\text { properties are ta }\end{array}$ & $\begin{array}{l}\text { ns NCC } 156 . \\
\text { ted chickpea } \\
\text { e identified } \\
\text { ompound } \\
\text { on-dependent } \\
\text { hroom flavour } \\
\text { ken from }\end{array}$ \\
\hline
\end{tabular}


Fig. 8 Metabolic flux analysis of L-lysine biosynthesis in $B$. amyloliquefaciens NCC 156 (yellow) and L. paracasei subsp. paracasei NCC 2511 (blue) during chickpea milk fermentation. The carbon flux through of L-lysine biosynthesis was investigated by monitoring the incorporation of ${ }^{13} \mathrm{C}$ from $\left[{ }^{13} \mathrm{C}_{4}\right] \mathrm{L}$-aspartate, added as a tracer to the medium, into L-lysine. As a control, naturally labelled L-aspartate was supplemented to the same amount instead. The data show the ${ }^{13} \mathrm{C}$ enrichment in total L-lysine, free extracellular L-lysine, and total L-aspartate after $20 \mathrm{~h}$ of fermentation, measured by GC/MS. The given summed fractional labelling (SFL) reflects the average enrichment of ${ }^{13} \mathrm{C}$ in each of the analytes. The corresponding values from the control experiment for total L-aspartate $(1.1 \pm 0.1 \%)$, total L-lysine $(1.1 \pm 0.1 \%)$, and free extracellular L-lysine $(1.1 \pm 0.1 \%)$ matched the theoretical values expected from natural ${ }^{13} \mathrm{C}$ abundance. They are shown as dashed lines. The significance of ${ }^{13} \mathrm{C}$ enrichment in each analyte was determined by comparison of the measured value against the naturally labelled control, and is marked accordingly $\left({ }^{*} p<0.05\right.$, $\left.{ }^{* *} p<0.01\right) . n=3$

NCC 2511 further revealed a significant capability to oxidize five-carbon to nine-carbon aldehydes into the corresponding acids. B. amyloliquefaciens NCC 156 also oxidized aldehydes, more selectively the odd chain compounds pentanal, heptanal and nonanal. Moreover, we tested flavour-related effects by supplementing branched chain amino acids (Fig. 9AB). B. amyloliquefaciens NCC 156 degraded leucine, isoleucine, and valine (spiked into the medium) into short chain fatty acids, whereas $L$. paracasei subsp. paracasei did not metabolize these amino acids.

\section{Discussion}

\section{Genome-based selection appears to be an efficient} strategy to identify L-lysine overproducers for chickpea milk fermentation

Since the early days of humankind, fermentation has been a natural approach to produce food, and today, fermented foods are more popular than ever [33, 34]. Given the magnitude of available microbes for plant milk fermentation (or even food fermentation in general), straightforward selection of the most appropriate microbes appears crucial. Previous approaches that successfully increased the L-lysine content in chickpea [16], soybean [13-15, 35], mung bean [17], and cowpea [18] found the corresponding microbes mainly only spontaneously and occasionally.

Here, potential L-lysine producers were systematically selected, based on their genomic repertoires. By strict filtering of genome sequences for key genes related to L-lysine synthesis and degradation, an initially high number of approximately 2,500 potential candidates was narrowed down to 31 strains that possessed the key genes lys $A$ and $\operatorname{dapF}$ for L-lysine biosynthesis, incomplete pathway sets for L-lysine degradation and fulfilled the QPS
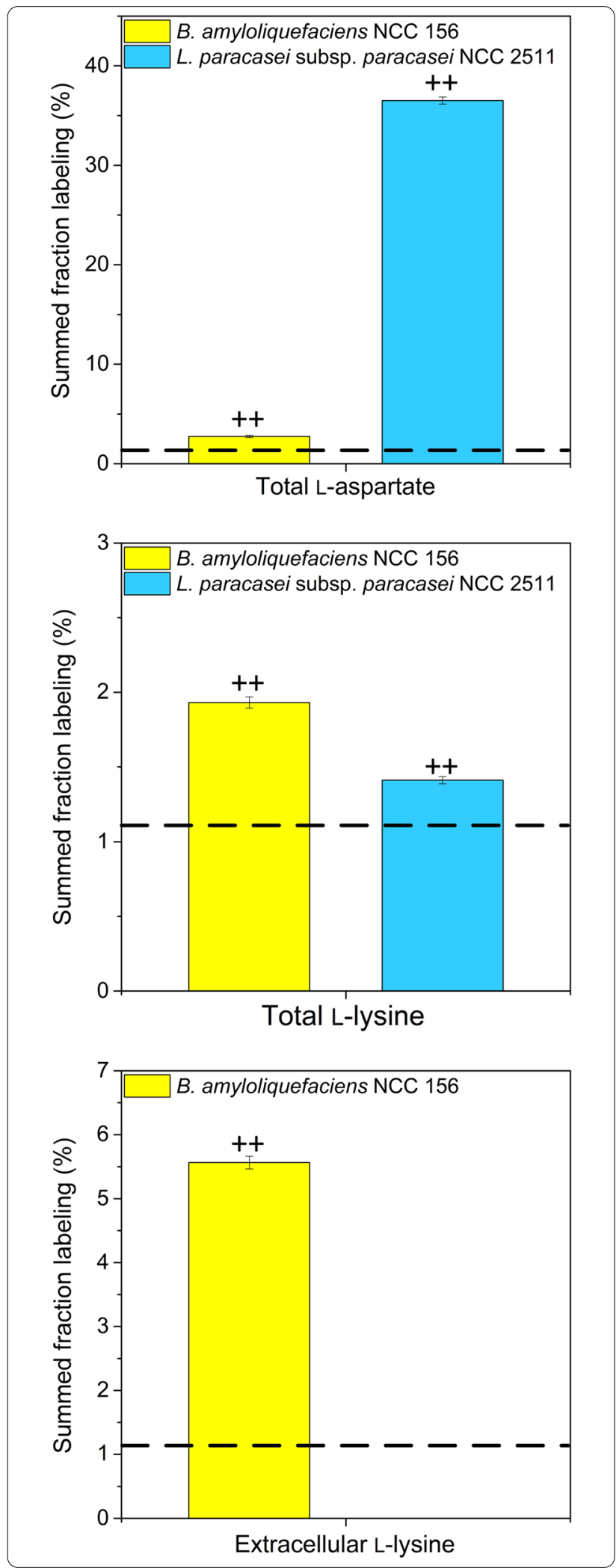


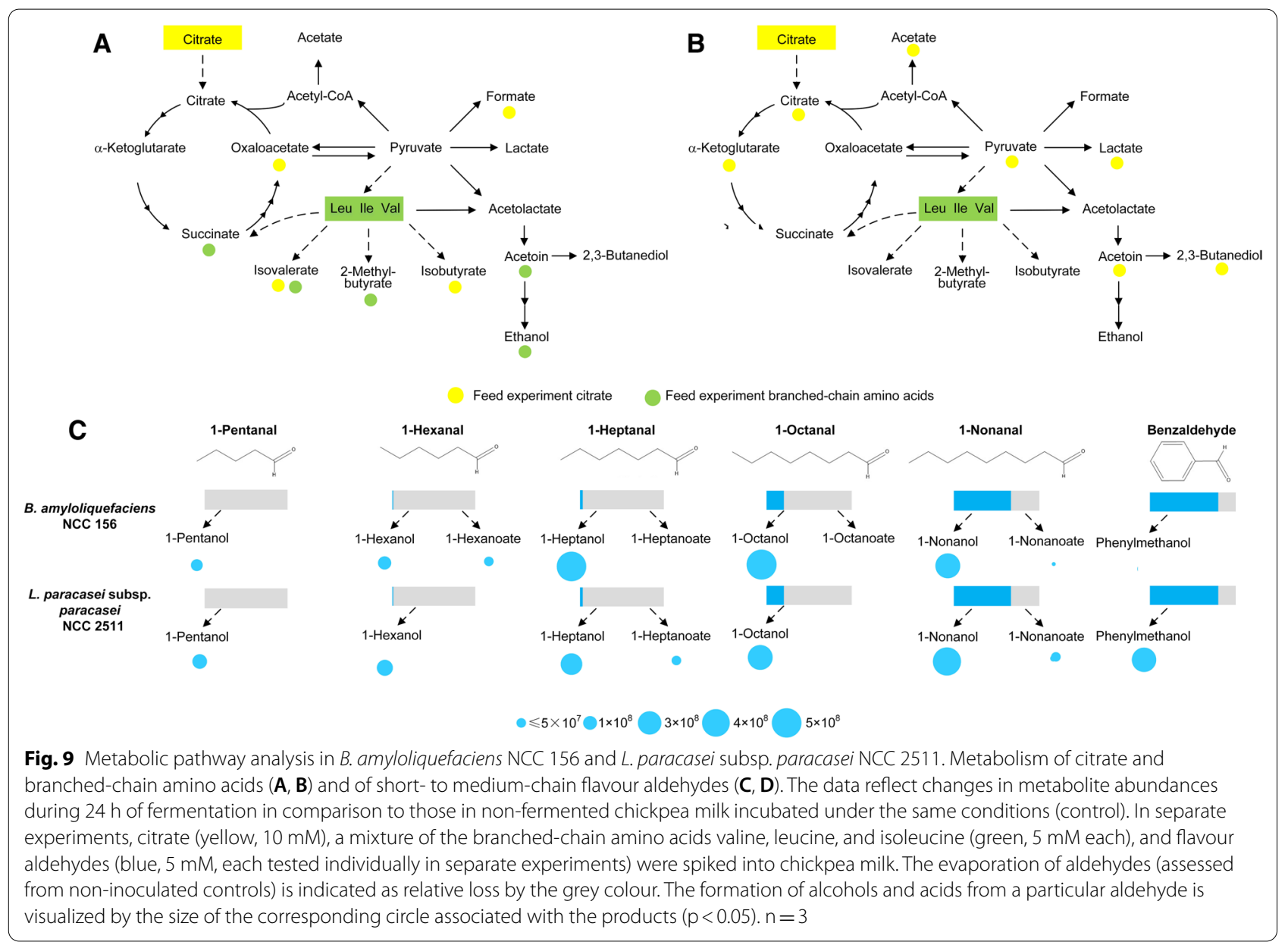

recommendation. The selected strains represented 10 different microbial genera and (given the low number) enabled straightforward experimental work. As a valuable proof-of-concept, $30 \%$ of all experimentally tested strains exhibited the desired phenotype in increasing the L-lysine content, and it appears promising to extend this genome-based selection approach to other plant milk fermentation processes and traits. Although our study could not yield a complete picture, it provided at least systematic insight into the pathways that supported L-lysine production most. Among the strains that exhibited growth and L-lysine accumulation, the majority (79\%) possessed a completely annotated acetylase pathway (AP), while $32 \%$ exhibited a complete succinylase pathway (SP), and two isolates had both routes in parallel. None of the strains used here contained the dehydrogenase pathway (DP). The different biosynthetic routes are widely abundant in nature: there are SP-using species such as Escherichia coli, Corynebacterium, Bacillus, and Lactobacillus [36-38], AP users such as certain Bacillus and Lacticaseibacillus [38, 39], and DP users such as Corynebacterium and some Bacillus species [36]. The AP and SP both supported L-lysine accumulation in chickpea milk, with a slightly better performance from the AP.

Among catabolic pathways and potential L-lysine withdrawal and degradation, there was no clear trend. The competing routes to homoserine $[40,41]$ and peptidoglycan $[42,43]$ did not have an impact. However, B. pumilus NCC 2962, the only strain tested that possessed a lysine decarboxylase (EC. 4.1.1.18)-encoding gene (Additional file 1: Fig. S2), dramatically decreased the L-lysine content so that future strain selection might consider potentially negative effects of this enzyme. Taken together, AP and SP genes appear to be genomic key features of well-performing L-lysine-producing strains. Based on performance, future focus should be given to strains of Lacticaseibacillus, Limosilactobacillus, Levilactobacillus, and Bacillus. Given that these genera are among the most widely used microbes for plant-based fermentation [44, 45], there seems striking potential ahead. 
B. amyloliquefaciens NCC 156 and L. paracasei subsp. paracasei NCC 2511 are drivers of a multi-benefit chickpea milk fermentation

Plant-based milk alternatives preferably exhibit the technical, nutritional, and organoleptic properties of cow milk, so researchers and developers in academia and industry must overcome certain challenges [1]. From a technical viewpoint, gelation of typically starchy plant materials during sterilization causes problems in downstream processing [46]. Conventional autoclaving and pasteurization failed as pre-treatment strategies due to the reasons mentioned above. The developed two-step heat treatment, however, provided a homogeneous and stable emulsion and was a valuable strategy for processing chickpea milk prior to fermentation at a small scale.

On the fermentation side, several goals had to be addressed: (i) improvement of the naturally low nutritional value of plant milks limited in amino acids [47], (ii) improvement of digestibility to avoid flatulence, diarrhoea, and other discomforts [48], and (iii) improvement of the typically unpleasant earthy and beany taste [49]. It is therefore an important outcome of this study that B. amyloliquefaciens NCC 156 and $L$. paracasei subsp. paracasei NCC 2511 addressed several of these major criteria well. As shown, they increased the L-lysine level by up to $43 \%$ (Fig. 3), largely removed indigestible sugars (Fig. 4EL), improved the amino acid profile (Fig. 4), and improved the flavour (Fig. 7). Based on their performance, they are well-performing microbes for chickpea milk fermentation. The multiple benefits delivered, and the food-grade approval associated with both strains suggest their great potential for use in industry.

In this regard, B. amyloliquefaciens NCC 156 and L. paracasei subsp. paracasei NCC 2511 stand in a prominent line with related microbes. For example, $B$. amyloliquefaciens strains are found in fermented legumebased foods, including doenjang and meju [50, 51], and are often regarded as probiotics due to their beneficial effects on functional food products [52]. Selected bacilli improved the L-lysine content in soy-based food [14, 53, 54]. L. paracasei subsp. paracasei NCC 2511 belongs to the group of facultative heterofermentative lactic acid bacteria (LAB), which are also widely used in dairy and plant-based milk fermentation [55-57] and known to exhibit probiotic properties $[58,59]$ and increase L-lysine levels, as shown for soy meal [60], soybean flour [14], and cowpea milk [18].

The efficient consumption of (also indigestible) oligosaccharides and the accumulation of maltose by $B$. amyloliquefaciens NCC 156 (obviously resulting from degraded starch) revealed its high glycosidic activity involving $\alpha$-galactosidase, $\beta$-fructosidase, and a-amylase
(Fig. 4DE, Additional file 1: Table S4) The enzymatic portfolio, also observed in other bacilli [61, 62], appeared valuable since it improved the digestibility and acceptability of the fermented product. L. paracasei subsp. paracasei NCC 2511 also exhibited $\beta$-fructosidase, $\alpha$-galactosidase, and $\alpha$-amylase activity but to a weaker extent (Fig. 4KL, Additional file 1: Table S4). According to previous studies, the glycolytic capacity among strains of $L$. paracase $i$ subsp. paracase $i$ and other lactobacilli is rather strain specific $[4,57,63-66]$.

Interestingly, the two microbes utilized nutrients differently. As a striking example, citrate stimulated the growth and L-lysine production of B. amyloliquefaciens NCC 156, which is an interesting finding given that sugars are mainly known to drive L-lysine overproduction [41]. In contrast, citrate triggered aroma development in L. paracasei subsp. paracasei NCC 2511 . Hereby, the organic acid was obviously converted into four-carbon dicarboxylic acids such as succinate and oxaloacetate via the TCA cycle and potentially also via citrate lyase and then triggered the production of acetate, acetoin, acetate, and smaller amounts of lactate $[67,68]$. B. amyloliquefaciens, lacking a citrate lyase pathway, instead used acid for growth.

\section{A rich set of microbial aroma compound conversions contributes to an improved flavour profile during chickpea milk fermentation}

Flavours are a major attribute that consumers consider when buying plant milk-derived products [69]. Unfortunately, plant-based milk alternatives are generally perceived as having a displeasing taste, probably because of previous experiences with less-appealing products in the market [49]. As shown here, unfermented chickpea milk contained various volatiles associated with an undesired taste (Fig. 7), a typical drawback for these types of plantbased raw materials [70]. Prominent beany and earthy off-flavours are caused by medium-chain aldehydes such as pentanal, hexanal, and heptanal [71], which originate from the oxidation of plant lipids and are also found in high amounts in other legume-based milks [71].

It can therefore be regarded as beneficial that $L$. paracasei subsp. paracasei NCC 2511 and B. amyloliquefaciens NCC 156 largely eliminated these aldehydes (Fig. 9C). As shown by spiking experiments, the major routes of elimination seemed to be one-step reductive and oxidative biotransformations into the corresponding alcohols and acids, respectively, mostly yielding a strong upgrade in flavour properties into sweet and fruity notes [72], although multistep bioconversion and de novo formation found in other microbes appeared possible as well [73]. 
Other flavour-related conversions involved entire pathways of carbon core metabolism, underlining the complexity involved. Citrate and branched-chain amino acids were identified as important precursors. Citrate metabolism in L. paracasei subsp. paracasei provided acetate, lactate, acetoin, and 2,3-butanediol, whereas valine, leucine and isoleucine degradation delivered isobutyrate, isovalerate, and 2-methylbutanoate. Based on the discovered link between the chickpea ingredient and specific flavours, screening for plant-based materials rich in such precursors to stimulate the formation of desired flavour notes appears promising [74]. As demonstrated, elevated citrate levels would also provide more L-lysine. An interesting possibility also seems to be the direct addition of such compounds to fermentation to generate beneficial fermentation products.

Maltol is also formed, and it contributes to a sweet caramel flavour and is released by the cleavage of antinutrient saponins during fermentation [75]. The metabolic origin of the removal of other compounds, such as 1-octen-3-ol and 2-pentyl-furan, remains to be elucidated, but their degradation surely reduces the undesired earthy and beany taste of chickpea flour [76]. Clearly, the overall aroma of (fermented) legume-based milk is not due to single chemicals but rather their exact mixture [70]. As such, the overall decrease in off-odour aldehydes plus the formation of favoured sweet and fruity alcohols, acids, ketones, and phenols is an important indication that sensory properties were significantly improved, but more work, e.g., using sophisticated electronic aroma sensing and personal aroma detection by skilled and trained sensory panellists, is needed to fully capture the underlying changes $[71,77,78]$.

\section{Conclusions}

In this work, a genome-based approach supported the selection of two well-performing strains for the fermentation of chickpea milk. As shown, each of the microbes exhibited multiple benefits: an improved L-lysine content due to de novo synthesis of the amino acid, which was proven in ${ }^{13} \mathrm{C}$ experiments; an improved digestibility due to the removal of raffinose and stachyose; and an improved flavour profile due the elimination of off-flavour aldehydes and the generation of sweet and fruity aromas. The origins of most of the desired traits were found at the metabolic pathway level to prove the microbial contributions, which we regard as important and valuable in terms of understanding the observed benefits as the results of natural processes catalysed by safe microbes, suggesting greater use of systems biology approaches [32, 79-81] to study food fermentation. In particular, the use of ${ }^{13} \mathrm{C}$ isotopes for flux analysis, applicable on a small scale [82], appears valuable in this regard.

Notably, each of the two microbes exhibited a unique signature. B. amyloliquefaciens NCC 156 showed a greater capability to grow, likely enabled by its stronger portfolio of hydrolytic enzymes, whereas $L$. paracasei subsp. paracasei NCC 2511 exhibited pronounced synthesis of selected beneficial molecules. In this regard, each of the two strains has its own benefits for use in fermentation of chickpea milk and appears promising for testing on other plant-based milks.

\section{Material and methods Microorganisms}

The microbial strains used in this work were obtained from the NCC (Nestlé Research Centre, Lausanne, Switzerland) (Additional file 1: Table S1). All strains were food-grade approved based on the qualified presumption of safety (QPS) recommendation [22]. They were maintained as frozen stocks in $30 \%$ glycerol $(\mathrm{v} / \mathrm{v})$ at $-80^{\circ} \mathrm{C}$.

\section{Genome-based strain selection}

The gene sequence information for strain selection was obtained from the NCC genome database [83]. The database was screened for the presence and absence of genes of interest using automated annotation. A proprietary database of enzyme domain profiles was used to screen all NCC genome proteins using NCBI's Reverse Position Specific Basic Local Alignment Search Tool (RPSBLAST) algorithm, constrained by minimum query coverage (60\%), minimum hit coverage $(60 \%$, [84]. A particular enzyme domain was regarded as present when the corresponding E-value was below 1E-3.

\section{Pre-culture medium}

Depending on individual nutrient requirements, different media were used for pre-cultivation of the strains. Most lactobacilli (L. helveticus, L. hilgardii, L. delbrueckii, L. plantarum, L. brevis, L. johnsonii, L. reuteri, L. paracasei, and L. acidophilus) were cultivated in de ManRogosa-Sharpe (MRS) medium, containing $52.0 \mathrm{~g}$ of MRS broth (Sigma-Aldrich, Steinheim, Germany) and $1.0 \mathrm{~mL}$ of Tween-80 per litre [85]. F. sanfranciscensis and L. pontis were grown in sanfrancisco medium [86], which was modified in this work and contained $10.0 \mathrm{~g}$ of tryptone (Becton Dickinson, Franklin Lakes, NJ, USA), $7.0 \mathrm{~g}$ of yeast extract (Becton Dickinson), $7.0 \mathrm{~g}$ of glucose, $7.0 \mathrm{~g}$ of fructose, $7.0 \mathrm{~g}$ of maltose monohydrate, $5.0 \mathrm{~g}$ of sodium acetate trihydrate, $5.0 \mathrm{~g}$ of di-ammonium hydrogen citrate, $2.5 \mathrm{~g}$ of $\mathrm{KH}_{2} \mathrm{PO}_{4}, 2.0 \mathrm{~g}$ of Lab Lemco powder (Oxoid, Thermo Fisher, Rockford, IL, USA), $2.0 \mathrm{~g}$ of sodium gluconate, $0.5 \mathrm{~g}$ of L-cysteine hydrochloride, $0.4 \mathrm{~g}$ of $\mathrm{MgSO}_{4} \cdot 7 \mathrm{H}_{2} \mathrm{O}, 0.1 \mathrm{~g}$ of $\mathrm{MnSO}_{4} \cdot \mathrm{H}_{2} \mathrm{O}, 0.05 \mathrm{~g}$ of 
$\mathrm{FeSO}_{4} \cdot 7 \mathrm{H}_{2} \mathrm{O}$, and $1.0 \mathrm{~mL}$ of Tween- 80 per litre. All Bifidobacterium strains were grown in MRS-Cys broth containing $52.0 \mathrm{~g}$ of MRS broth, $0.5 \mathrm{~g}$ of cysteine hydrochloride, and $1.0 \mathrm{~mL}$ of Tween- 80 per litre. The strains of Bacillus were grown in modified tryptic soy broth containing $17.0 \mathrm{~g}$ of tryptone (Becton Dickinson), $5.0 \mathrm{~g}$ of $\mathrm{NaCl}, 3.0 \mathrm{~g}$ of soytone (Becton Dickinson), $2.5 \mathrm{~g}$ of $\mathrm{K}_{2} \mathrm{HPO}_{4}$, and $1.0 \mathrm{~mL}$ of $30 \%$ silicone antifoam (SigmaAldrich) per litre. C. stationis was cultivated in brain heart infusion cysteine (BHI-Cys) broth containing $37.0 \mathrm{~g}$ of brain heart infusion (Becton Dickinson) and $0.5 \mathrm{~g}$ of L-cysteine hydrochloride per litre.

\section{Chickpea milk medium}

A chickpea suspension was prepared by mixing $10 \%$ $(w / w)$ commercially produced chickpea flour (E. Zwicky AG, Müllheim-Wigoltingen, Switzerland) with deionized water. Flour from one batch $(25 \mathrm{~kg})$ was used in all experiments. A two-step heat treatment was applied for sterilization. First, the suspension was stirred $(250 \mathrm{rpm}$, $\left.2 \mathrm{~h}, 75{ }^{\circ} \mathrm{C}\right)$, which was followed by autoclaving $\left(121{ }^{\circ} \mathrm{C}\right.$, $15 \mathrm{~min}$ ). Prior to fermentation, the suspension was manually homogenized. In ${ }^{13} \mathrm{C}$ tracer experiments, $98 \%\left[{ }^{13} \mathrm{C}_{4}\right]$ L-aspartate (Eurisotop, Gif-Sur-Yvette, France) was added to a final concentration of $11 \mathrm{mM}$, whereas controls received the same amount of naturally labelled L-aspartate. In further experiments, selected nutrients were added to chickpea milk from sterilized stocks before fermentation to investigate their impact: (i) citrate $(10 \mathrm{mM})$, (ii) a mixture of the branched-chain amino acids valine, leucine, and isoleucine (5 $\mathrm{mM}$ each), and (iii) volatile aldehydes such as pentanal, hexanal, heptanal, octanal, nonanal, and benzaldehyde ( $5 \mathrm{mM}$ each in separate experiments).

\section{Chickpea milk fermentation}

Strains were inoculated from a glycerol stock $(200 \mu \mathrm{L})$ into $10 \mathrm{~mL}$ of pre-culture medium and incubated overnight. The medium and growth temperatures were individually adapted (Additional file 1: Table S1). In addition, different conditions were used to grow obligate anaerobic, aerotolerant and obligate aerobic strains (Additional file 1: Table S1). Obligate anaerobic strains were incubated in $20 \mathrm{~mL}$ tubes filled with $10 \mathrm{~mL}$ of pre-culture medium and placed in an anaerobic jar at $9-13 \% \mathrm{CO}_{2}$ (anaerobic atmosphere generation bags, Merck, Darmstadt, Germany). Aerotolerant strains were cultivated in the same tubes $(20 \mathrm{~mL}$ filled with $10 \mathrm{~mL}$ of medium) but placed under ambient air. Obligate aerobic strains were cultivated in $10 \mathrm{~mL}$ of pre-culture medium in $100 \mathrm{~mL}$ non-baffled shake flasks on a rotary shaker $(130 \mathrm{rpm}$, $80 \%$ humidity, Infors, Bottmingen, Switzerland).
Subsequently, cells were collected $\left(5,000 \times g, 5 \mathrm{~min}, 4{ }^{\circ} \mathrm{C}\right)$ and used to inoculate a second pre-culture grown under the same conditions overnight, which was then used as inoculum for the main chickpea milk fermentation. Depending on the studied microbe, the main fermentation was then conducted in $20 \mathrm{~mL}$ of medium in $200 \mathrm{~mL}$ glass bottles under a $\mathrm{CO}_{2}$ atmosphere (obligate anaerobes) or ambient air (aerotolerant) and in $100 \mathrm{~mL}$ nonbaffled shake flasks (obligate aerobes).

Potential evaporation loss during fermentation was monitored using non-inoculated controls and used to correct the obtained data [32]. The non-inoculated cultures further served as controls to verify the sterility of the raw material and monitor the occurrence of abiotic changes that potentially altered the composition. In selected experiments, the $\mathrm{pH}$ value and dissolved oxygen (DO) level were monitored in shake flasks with immobilized sensor spots and fluorescence detection (PreSens Precision Sensing $\mathrm{GmbH}$, Regensburg, Germany) [87]. Each fermentation was conducted as biological triplicates.

\section{Quantification of colony-forming units}

The estimation of cfu was based on plate serial dilution spotting [88]. Serial dilutions from a $1 \mathrm{~mL}$ sample were prepared in $0.85 \% \mathrm{NaCl}(\mathrm{w} / \mathrm{v})$ containing $1 \mathrm{~g} \mathrm{~L}^{-1}$ tryptone (Becton Dickinson). All measurements were conducted in duplicate.

\section{Quantification of chickpea milk moisture}

Samples of $2 \mathrm{~g}$ were freeze-dried for $48 \mathrm{~h}$. Then, the remaining total solids were quantified by measuring the residual weight.

\section{Protein and amino acid quantification}

For the quantification of total amino acids, samples were homogenized ( $2 \mathrm{~mL}$ Precellys Lysing Kits filled with $1.4 \mathrm{~mm}$ ceramic balls, Bertin, Montigny-leBretonneux, France) using a homogenizer (5000 rpm, $3 \times 90 \mathrm{~s}$ with $30 \mathrm{~s}$ breaks on ice in between). Approximately $10 \mathrm{mg}$ of a homogenized sample was then hydrolysed $\left(24 \mathrm{~h}, 6 \mathrm{M} \mathrm{HCl}, 100{ }^{\circ} \mathrm{C}\right)$, dried, resuspended in deionized water, and filtered $(0.22 \mu \mathrm{m}$, Millipore, Merck, Darmstadt, Germany). The obtained amino acids were analysed by HPLC (Agilent 1100 Infinity, Agilent Technologies, Waldbronn, Germany) with pre-column derivatization with ortho-phthaldialdehyde and 2-aminobutyrate as an internal standard [89]. In short, the analytes were separated at $40{ }^{\circ} \mathrm{C}$ and a flow rate of $1 \mathrm{~mL} \mathrm{~min}^{-1}$ on a reversed-phase column (Gemini $5 \mu \mathrm{m} \mathrm{C} 18110 \AA ̊ 丿, 150 \times 4.6 \mathrm{~mm}$, Phenomenex, Torrance, CA, USA) using the following gradient of eluent $\mathrm{A}\left(40 \mathrm{mM} \mathrm{Na} \mathrm{N}_{2} \mathrm{HPO} 4,7.7 \mathrm{mM}\right.$ sodium 
azide, $\mathrm{pH} 7.8)$ and eluent $\mathrm{B}(45 \%$ acetonitrile, $45 \%$ methanol, $10 \%$ deionized water): $0-45 \%$ B from 0 to $45 \mathrm{~min}, 45$ to $61 \%$ B from 45 to $47 \mathrm{~min}, 61$ to $82 \%$ B from 47 to $48 \mathrm{~min}, 82$ to $100 \% \mathrm{~B}$ from 48 to $48.5 \mathrm{~min}$, $100 \%$ B from 48.5 to $50.5 \%$, and 100 to $0 \%$ B from 51 to $53 \mathrm{~min}$. The analytes were detected by fluorescence (340/450 nm). L-cysteine, L-methionine, and L-tryptophan were degraded during the hydrolysis process so that these amino acids were not measurable, whereas $\mathrm{L}$-glutamine and $\mathrm{L}$-asparagine were converted into L-glutamate and L-aspartate, respectively, so that the obtained data reflected the lumped pools [90]. The total protein amount was calculated by summing up the level of the individual amino acids. For the quantification of free amino acids, $1 \mathrm{~mL}$ fermentation sample was centrifuged $\left(20,000 \times g, 10 \mathrm{~min}, 4{ }^{\circ} \mathrm{C}\right)$. The obtained supernatant was filtered $(0.22 \mu \mathrm{m}$, Millipore $)$ and analysed as described above.

\section{Quantification of sugars, organic acids, and alcohols}

Disaccharides (sucrose and maltose) and larger oligomers (raffinose, stachyose, and verbascose) were quantified in filtered samples $(0.22 \mu \mathrm{m}$, Millipore) using HPLC (Agilent 1260 Infinity Series, Agilent Technologies). The analytes were separated on a sulfonated spherical PS/DVB resin (VA 300/7.8 Nucleogel sugar $\mathrm{Pb}$, Macherey-Nagel, Düren, Germany) with deionized water as the mobile phase $\left(80{ }^{\circ} \mathrm{C}\right.$, $0.4 \mathrm{~mL} \mathrm{~min}^{-1}$ ) and detected via the refraction index. External standards were used for quantification. The concentrations of organic acids (lactate, acetate, pyruvate, citrate, $\alpha$-ketoglutarate, isobutyrate, isovalerate) and alcohols (acetoin, ethanol, 2,3-butanediol) in filtered samples $(0.22 \mu \mathrm{m}$, Millipore $)$ were determined using HPLC (Agilent 1260 Infinity Series, Agilent Technologies) with ion exclusion (Aminex HPX-87H, $300 \times 7.8 \mathrm{~mm}$, Bio-Rad, Hercules, CA, USA), $12 \mathrm{mM}$ $\mathrm{H}_{2} \mathrm{SO}_{4}$ as the mobile phase $\left(45^{\circ} \mathrm{C}, 0.5 \mathrm{~mL} \mathrm{~min}^{-1}\right)$, and refractive index detection [91]. External standards were used for quantification.

\section{Quantification of lipids}

Analysis of the lipid (fat) content was conducted after hexane/isopropanol extraction [92]. Briefly, $5 \mathrm{~mL}$ of hexane/isopropanol (3:2) was added to a $1 \mathrm{~mL}$ sample. The mixture was incubated for $24 \mathrm{~h}$ at $18{ }^{\circ} \mathrm{C}$ and $230 \mathrm{rpm}$. After addition of $5 \mathrm{~mL}$ of $\mathrm{Na}_{2} \mathrm{SO}_{4}(0.47 \mathrm{M})$, the extract was centrifuged at $4000 \times g$ for $10 \mathrm{~min}$. The upper liquid phase was collected and extracted once more using $5 \mathrm{~mL}$ of hexane/isopropanol (7:2). Both lipid fractions were then combined and dried under nitrogen flow until a constant weight was reached. The remaining solids were weighed and used to calculate the lipid content.
Mass isotopomer analysis by GC-MS and processing of ${ }^{13} \mathrm{C}$ data

In isotopic tracer experiments, the ${ }^{13} \mathrm{C}$ labelling patterns of L-lysine and L-aspartate were analysed using GC-MS [32]. For ${ }^{13} \mathrm{C}$ labelling analysis of the total amino acids, fermentation samples were homogenized as described above. Approximately $10 \mu \mathrm{L}$ of a homogenized sample was hydrolysed $\left(24 \mathrm{~h}, 6 \mathrm{M} \mathrm{HCl}, 100^{\circ} \mathrm{C}\right)$, filtered $(0.22 \mu \mathrm{m}$, Millipore), dried under a nitrogen flow, and dissolved in $50 \mu \mathrm{L}$ of $\mathrm{N}, \mathrm{N}$-dimethylformamide (1\% (v/v) pyridine). For ${ }^{13} \mathrm{C}$ analysis of free L-lysine, a $1 \mathrm{~mL}$ sample was centrifuged $\left(20,000 \times g, 10 \mathrm{~min}, 4{ }^{\circ} \mathrm{C}\right)$. An aliquot of $50 \mu \mathrm{L}$ of the obtained supernatant was filtered $(0.22 \mu \mathrm{m}$, Millipore), dried under a nitrogen flow, and dissolved in 50 $\mu \mathrm{L}$ of $\mathrm{N}, \mathrm{N}$-dimethylformamide ( $1 \%(\mathrm{v} / \mathrm{v})$ pyridine). The amino acids were then derivatized at $80{ }^{\circ} \mathrm{C}$ for $30 \mathrm{~min}$ into the corresponding $t$-butyldimethylsilyl derivatives using $50 \mu \mathrm{L}$ of $\mathrm{N}$-methyl- $t$-butyldimethylsilyl-trifluoroacetamide (MBDSTFA, Macherey-Nagel). Mass spectrometric analysis was conducted on a GC-MS instrument (Agilent 5977 A MSD, Agilent Technologies) equipped with an HP-5MS column $(30 \mathrm{~m}, 0.250 \mathrm{~mm}, 0.25 \mu \mathrm{m}$, Agilent Technologies) using helium as the carrier gas $\left(1.7 \mathrm{~mL} \mathrm{~min}^{-1}\right)$ and the following temperature gradient: $120{ }^{\circ} \mathrm{C}(0-2 \mathrm{~min}), 8{ }^{\circ} \mathrm{C} \min ^{-1}(2-12 \mathrm{~min}), 10{ }^{\circ} \mathrm{C} \min ^{-1}$ (12-24.5 min), and $325{ }^{\circ} \mathrm{C}(24.5-27 \mathrm{~min})$. The [M-57] ion cluster of the derivatized amino acids $(\mathrm{m} / \mathrm{z} 431$ for L-lysine, $m / z 418$ for $\mathrm{L}$-aspartate) was selected to determine the ${ }^{13} \mathrm{C}$ labelling pattern, as it represented the entire carbon backbone [90]. All samples were first measured in scan mode to exclude isobaric matrix interference with the analytes of interest and verify that the selected ion clusters were suited for ${ }^{13} \mathrm{C}$ quantification. Subsequently, labelling patterns were determined in duplicate using selective ion monitoring. The derived mass isotopomer distributions were corrected for natural isotopes [93] and used to derive the SFL [32]. The SFL expressed the labelling pattern as the average ${ }^{13} \mathrm{C}$ enrichment of the included carbon. For method validation, naturally labelled samples were treated and analysed as given above.

\section{GC-MS analysis of volatile flavour and fragrance compounds}

Analysis of volatiles was based on headspace solid-phase microextraction GS-MS (HS-SPME-GC-MS) [94] using a PAL RSI 120 autosampler (CTC Analytics, Zwingen, Switzerland) coupled to a GC-MS instrument (Agilent 8890 GC system, Agilent Technologies). Samples were immediately processed after collection. Approximately $5 \mathrm{~mL}$ of broth was amended with $1 \mathrm{~g}$ of $\mathrm{NaCl}$ and incubated for $20 \mathrm{~min}$ at $40^{\circ} \mathrm{C}$ in a $20 \mathrm{~mL}$ sample vial at a shaking rate of $400 \mathrm{rpm}$. Afterwards, an SPME fibre (coated with $65 \mu \mathrm{m}$ divinylbenzene/ 
polydimethylsiloxane and preconditioned for $1 \mathrm{~h}$ at $260{ }^{\circ} \mathrm{C}$, Agilent Technologies) was exposed to the headspace of the vial at a depth of $40 \mathrm{~mm}$ for $20 \mathrm{~min}$ to absorb the volatiles. Then, the fibre was introduced and incubated in the injection port of the GC-MS instrument $\left(300{ }^{\circ} \mathrm{C}, 3 \mathrm{~min}\right)$ for desorption. The injector was operated in splitless mode. The analytes were separated on an HP-5MS column (30 m, $0.250 \mathrm{~mm}, 0.25 \mu \mathrm{m}$, Agilent Technologies) using helium as the carrier gas $\left(0.4 \mathrm{~mL} \mathrm{~min}^{-1}\right)$ and the following temperature gradient: $35^{\circ} \mathrm{C}$ for $3 \mathrm{~min}$, increase to $210{ }^{\circ} \mathrm{C}$ at $6{ }^{\circ} \mathrm{C} \mathrm{min}{ }^{-1}$, and $210{ }^{\circ} \mathrm{C}$ for $10 \mathrm{~min}$. Chromatograms were recorded by monitoring the total ion current (TIC) over a mass range of 30 to $300 \mathrm{~m} / z$. Following signal deconvolution (Agilent Chemstation, Agilent Technologies), analytes were identified based on their mass spectra against the NIST/EPA/NIH Mass Spectral Library (NIST 08), and corresponding area counts were collected for quantification. Where needed, synthetic standards were used to support the identification. All analytics were conducted in triplicate.

\section{Data processing and statistical analysis}

All results displayed in Figures and Tables are shown as the mean values \pm standard deviations (SDs). Statistical evaluation of the data was conducted by one-way analysis of variance (ANOVA), followed by Fisher's least significant difference (LSD) test and Duncan's test. Differences in values were considered significant when the $P$ value was less than $0.05(+)$ and $0.01(++)$. Statistical analyses were performed using SPSS (version 24.0).

\section{Supplementary Information}

The online version contains supplementary material available at https://doi. org/10.1186/s12934-021-01595-2.

Additional file 1: Table S1. Growth conditions and media used to preculture the different strains. Table S2. Microbial growth during chickpea milk fermentation. The data are given as (colony forming units) $m L-1 . n=3$. Table S3. The number of locus in B. amyloliquefaciens NCC 156 and L. paracasei subsp. paracasei NCC 2511 encoding functional enzymes invoving in flavor formation,pyruvate, and butanoate metabolism. Table S4. The number of locus in B. amyloliquefaciens NCC 156 and L. paracasei subsp. paracasei NCC 2511 encoding functional enzymes invoving in carbohydrate degradation and citrate metabolism. Fig. S1. Pre-treatment strategies for the processing of chickpea flour suspensions prior to microbial fermentation. Phase separation for the untreated milk (A), contamination of non-inoculated milk after pasteurization $\left(63^{\circ} \mathrm{C}, 5 \mathrm{~h}\right)(\mathrm{B})$, gelation and phase separation after stronger heating $\left(90^{\circ} \mathrm{C}, 30 \mathrm{~min}\right)(\mathrm{C})$, gelation and phase separation after autoclaving $\left(121^{\circ} \mathrm{C}, 15 \mathrm{~min}\right)$, generation of homogeneous and sterile suspension after a two-step treatment that included combined heating and stirring $\left(2 \mathrm{~h}, 75^{\circ} \mathrm{C}, 250 \mathrm{rpm}\right)$ and autoclaving $\left(121^{\circ} \mathrm{C}, 15 \mathrm{~min}\right)(\mathrm{E})$. The sterility of pasteurized milk (A) and two-step treated milk (D), was evaluated by non-inoculated incubation for $48 \mathrm{~h}$ at $37^{\circ} \mathrm{C}$. Fig. S2. Genomic repertoire of food-grade microbes linked to I-lysine metabolism: pathways for I-lysine biosynthesis (LSP), pathways competing with I-lysine biosynthesis for carbon precursors (PCP), and pathways for I-lysine degradation (LDP). The presence (yellow) and absence (blue) of corresponding key genes (Fig. 1) is indicated by colour.
Acknowledgements

This work is dedicated to the memory of Dr. Judith Becker $\left(^{*}\right.$ 2.2. 1981, † 27.4. 2021), our close and cherished colleague at the Institute of Systems Biotechnology, Saarland University, and our true friend.

\section{Authors' contributions}

All authors conducted bioinformatic strain selection. MT and MF developed GC/MS-based flavour extraction and analytics. MT performed all experiments, including fermentation and associated analytics. MF supported HPLC and GC/ MS analytics. CW conceived, supervised, and structured the work. MT and CW wrote the first draft of the manuscript and drew all figures. All authors critically commented, improved, and approved the final manuscript.

\section{Funding}

Open Access funding enabled and organized by Projekt DEAL. This study was funded by Nestec Ltd. (Vevey, Switzerland), which was merged with Société des Produits Nestlé SA on 1 June 2019.

\section{Availability of data and materials}

The dataset(s) supporting the conclusions of this article are all included within the article.

\section{Declarations}

Ethics approval and consent to participate

Not applicable. The manuscript does not contain data collected from humans or animals.

\section{Consent for publication}

Not applicable.

\section{Competing interests}

Christoph J. Bolten, Biljana Bogicevic, Lijuan Ye, and Rosa Agaro-Börner are employed by Nestlé Research, Switzerland, which is part of Société des Produits Nestlé SA, a wholly owned subsidiary of Nestlé SA. Nestec Ltd. (Vevey, Switzerland) has filed a patent application related to this study, including Muzi Tangyu and Christoph Wittmann as inventors. Michel Fritz declares that he has no competing interests.

\section{Author details}

${ }^{1}$ Institute of Systems Biotechnology, Saarland University, Saarbrücken, Germany. ${ }^{2}$ Nestlé Research Center, Lausanne, Switzerland. ${ }^{3}$ Nestlé Product Technology Center Food, Singen, Germany.

Received: 11 March 2021 Accepted: 15 May 2021

Published online: 28 May 2021

\section{References}

1. Tangyu M, Müller J, Bolten CJ, Wittmann C. Fermentation of plant-based milk alternatives for improved flavour and nutritional value. Appl Microbiol Biotechnol. 2019;103:9263-75.

2. Fu Y-H, Zhang F-C. Changes in isoflavone glucoside and aglycone contents of chickpea yoghurt during fermentation by Lactobacillus bulgaricus and Streptococcus thermophilus. J Food Process Preserv. 2013;37:744-50.

3. Kishor K, David J, Tiwari S, Singh A, Rai BS. Nutritional composition of chickpea (Cicer arietinum) milk. Int J Chem Stud. 2017;5:1941-4.

4. Li W, Wei M, Wu J, Rui X, Dong M. Novel fermented chickpea milk with enhanced level of $\gamma$-aminobutyric acid and neuroprotective effect on PC12 cells. PeerJ. 2016:4:e2292.

5. Chavan J, Kadam S, Salunkhe D, Beuchat LR. Biochemistry and technology of chickpea (Cicer arietinum L.) seeds. Crit Rev Food Sci Nutr. 1987;25:107-58.

6. Ribeiro R, Melo IP. Composition and nutritive value of chickpea. Options Mediterr Serie Semin. 1990;9:107-11.

7. Sethi S, Tyagi SK, Anurag RK. Plant-based milk alternatives an emerging segment of functional beverages: a review. J Food Sci Technol. 2016;53:3408-23. 
8. Flodin NW. The metabolic roles, pharmacology, and toxicology of lysine. J Am Coll Nutr. 1997;16:7-21.

9. Rachwa-Rosiak D, Nebesny E, Budryn G. Chickpeas-composition, nutritional value, health benefits, application to bread and snacks: a review. Crit Rev Food Sci Nutr. 2015;55:1137-45.

10. Csapó J, Salamon S, Lóki K, Csapó-Kiss Z. Composition of mare's colostrum and milk II. Protein content, amino acid composition and contents of macro-and micro-elements. Acta Univ Sapient Ser Aliment. 2009:2:133-48.

11. Onyesom I, Enaholo A, Mordi J. Effect of processing techniques on the contents of flatulence factors and emulsion properties of cowpea (Vigna unguiculata). J Appl Sci Environ Manage. 2005;9:65-72.

12. Aguirre L, Garro MS, de Giori GS. Enzymatic hydrolysis of soybean protein using lactic acid bacteria. Food Chem. 2008;111:976-82.

13. Frias J, Song Y, Martínez-Villaluenga C, De Mejia EG, Vidal-Valverde C. Fermented soyabean products as hypoallergenic food. Proc Nutr Soc. 2008. https://doi.org/10.1017/S0029665108006484.

14. Frias J, Song YS, Martínez-Villaluenga C, De Mejia EG, Vidal-Valverde C. Immunoreactivity and amino acid content of fermented soybean products. J Agric Food Chem. 2008:56:99-105.

15. Ghosh D, Chattoraj DK, Chattopadhyay P. Studies on changes in microstructure and proteolysis in cow and soy milk curd during fermentation using lactic cultures for improving protein bioavailability. J Food Sci Technol. 2013;50:979-85.

16. Reyes-Moreno C, Cuevas-Rodríguez E, Milán-Carrillo J, Cárdenas-Valenzuela O, Barrón-Hoyos J. Solid state fermentation process for producing chickpea (Cicer arietinum L.) tempeh flour Physicochemical and nutritional characteristics of the product. J Sci Food Agric. 2004;84:271-8.

17. Khalil AA. Nutritional improvement of an Egyptian breed of mung bean by probiotic lactobacilli. Afr J Biotechnol. 2006;5:206-12.

18. Sanni A, Onilude A, Adeleke E. Preparation and characteristics of lactic acid fermented cowpea milk. Z Lebensm Unters Forsch. 1999:208:225-9.

19. Santos CC, Libeck BS, Schwan RF. Co-culture fermentation of peanutsoy milk for the development of a novel functional beverage. Int J Food Microbiol. 2014;186:32-41.

20. Ray RC, Joshi V. Fermented foods: past, present and future. In: Ramesh C, Ray MD, editors. Microorganisms and fermentation of traditional foods. Boca Raton: CRC Press; 2014. p. 1-36.

21. Becker J, Rohles CM, Wittmann C. Metabolically engineered Corynebacterium glutamicum for bio-based production of chemicals, fuels, materials, and healthcare products. Metab Eng. 2018:50:122-41.

22. Ricci A, Allende A, Bolton D, Chemaly M, Davies R, Girones R, Herman L, Koutsoumanis K, Lindqvist R, Nørrung B. Scientific opinion on the update of the list of QPS-recommended biological agents intentionally added to food or feed as notified to EFSA. EFSA J. 2017;15:4663.

23. Brillet A, Pilet M-F, Prevost $H$, Bouttefroy A, Leroi F. Biodiversity of Listeria monocytogenes sensitivity to bacteriocin-producing Carnobacterium strains and application in sterile cold-smoked salmon. J Appl Microbiol. 2004;97:1029-37.

24. Porto MCW, Kuniyoshi TM, Azevedo P, Vitolo M, Oliveira RS. Pediococcus spp.: an important genus of lactic acid bacteria and pediocin producers. Biotechnol Adv. 2017:35:361-74.

25. Wade M, Strickland MT, Osborne JP, Edwards CG. Role of Pediococcus in winemaking. Aust J Grape Wine Res. 2019;25:7-24.

26. Wallace TC, Murray R, Zelman KM. The nutritional value and health benefits of chickpeas and hummus. Nutrients. 2016;8:766.

27. Jukanti AK, Gaur PM, Gowda C, Chibbar RN. Nutritional quality and health benefits of chickpea (Cicer arietinum L.): a review. Br J Nutr. 2012:108:S11-26.

28. Guo H, Pang K, Zhang X, Zhao L, Chen S, Dong M, Ren F. Composition, physiochemical properties, nitrogen fraction distribution, and amino acid profile of donkey milk. Int J Dairy Sci. 2007;90:1635-43.

29. Liu M, Nauta A, Francke C, Siezen RJ. Comparative genomics of enzymes in flavor-forming pathways from amino acids in lactic acid bacteria. Appl Environ Microbiol. 2008;74:4590-600.

30. Smit BA, Engels WJ, Smit G. Branched chain aldehydes: production and breakdown pathways and relevance for flavour in foods. Appl Microbiol Biotechnol. 2009;81:987-99.

31. Savoy de Giori G, Agiorre L, Marazza J, Garro MS. An overview of lactic acid bacteria applications for healthful soy foods development. In:
Mozzi F, Raya RR, Vignolo GM, editors. Biotechnology of lactic acid bacteria: novel applications. Ames, lowa: Blackwell; 2010. p. 289-300.

32. Schwechheimer SK, Becker J, Peyriga L, Portais J-C, Sauer D, Müller R, Hoff B, Haefner S, Schröder H, Zelder O. Improved riboflavin production with Ashbya gossypii from vegetable oil based on ${ }^{13} \mathrm{C}$ metabolic network analysis with combined labeling analysis by GC/MS, LC/MS, 1D, and 2D NMR. Metab Eng. 2018;47:357-73.

33. Adler P, Bolten CJ, Dohnt K, Hansen CE, Wittmann C. Core fluxome and meta fluxome of lactic acid bacteria under cocoa pulp fermentation simulating conditions. Appl Environ Microbiol. 2013;79:5670-81.

34. Adler P, Bolten CJ, Dohnt K, Hansen CE, Wittmann C. Core fluxome and metafluxome of lactic acid bacteria under simulated cocoa pulp fermentation conditions. Appl Environ Microbiol. 2013;79:5670-81.

35. Do Amaral Santos CCA, Da Silva Libeck B, Schwan RF. Co-culture fermentation of peanut-soy milk for the development of a novel functional beverage. Int J Food Microbiol. 2014;186:32-41.

36. Dogovski C, Atkinson SC, Dommaraju SR, Downton M, Hor L, Moore S, Paxman JJ, Peverelli MG, Qiu TW, Reumann M. Enzymology of bacterial lysine biosynthesis. Biochemistry. 2012;1:225-62.

37. Schrumpf B, Schwarzer A, Kalinowski J, Pühler A, Eggeling L, Sahm H. A functionally split pathway for lysine synthesis in Corynebacterium glutamicium. J Bacteriol. 1991;173:4510-6.

38. Hao P, Zheng H, Yu Y, Ding G, Gu W, Chen S, Yu Z, Ren S, Oda M, Konno T. Complete sequencing and pan-genomic analysis of Lactobacillus delbrueckii subsp. bulgaricus reveal its genetic basis for industrial yogurt production. PLoS ONE. 2011;6(1):e15964.

39. Cahyanto MN, Kawasaki H, Nagashio M, Fujiyama K, Seki T. Regulation of aspartokinase, aspartate semialdehyde dehydrogenase, dihydrodipicolinate synthase and dihydrodipicolinate reductase in Lactobacillus plantarum. Microbiology. 2006;152:105-12.

40. Nelofer R, Syed Q, Baig S, Nadeem M. _-Lysine production by the homoserine auxotrophic mutant of Corynebacterium glutamicum in stirrer fermenter. Pak J Zool. 2007;39:159.

41. Becker J, Klopprogge C, Wittmann C. Metabolic responses to pyruvate kinase deletion in lysine producing Corynebacterium glutamicum. Microb Cell Fact. 2008;7:8.

42. Smith CA. Structure, function and dynamics in the mur family of bacterial cell wall ligases. J Mol Biol. 2006;362:640-55.

43. Xu J, Han M, Zhang J, Guo Y, Zhang W. Metabolic engineering Corynebacterium glutamicum for the ${ }_{\perp}$-lysine production by increasing the flux into $L^{-l y s i n e ~ b i o s y n t h e t i c ~ p a t h w a y . ~ A m i n o ~ A c i d s . ~}$ 2014:46:2165-75.

44. Jeske S, Zannini E, Arendt EK. Past, present and future: The strength of plant-based dairy substitutes based on gluten-free raw materials. Food Res Int. 2018;110:42-51.

45. Steinkraus KH. Classification of fermented foods: worldwide review of household fermentation techniques. Food Control. 1997:8:311-7.

46. Mäkinen OE, Wanhalinna V, Zannini E, Arendt EK. Foods for special dietary needs: Non-dairy plant-based milk substitutes and fermented dairy-type products. Crit Rev Food Sci Nutr. 2016;56:339-49.

47. Millward DJ. The nutritional value of plant-based diets in relation to human amino acid and protein requirements. Proc Nutr Soc. 1999.58:249-60.

48. Onyesom I, Enaholo AT, Mordi J. Effect of processing techniques on the contents of flatulence factors and emulsion properties of cowpea (Vigna unguiculata). J Appl Sci Environ Mgt. 2005;9:2.

49. Wansink B, Sonka S, Goldsmith P, Chiriboga J, Eren N. Increasing the acceptance of soy-based foods. J Int Food Agribus Mark. 2005;17:35-55.

50. Lee JY, Shim JM, Yao Z, Liu X, Lee KW, Kim H-J, Ham K-S, Kim JH. Antimicrobial activity of Bacillus amyloliquefaciens EMD17 isolated from Cheonggukjang and potential use as a starter for fermented soy foods. Food Sci Biotechnol. 2016;25:525-32.

51. Dakwa S, Sakyi-Dawson E, Diako C, Annan NT, Amoa-Awua WK. Effect of boiling and roasting on the fermentation of soybeans into dawadawa (soy-dawadawa). Int J Food Microbiol. 2005;104:69-82.

52. Urdaci M, Pinchuk I. Antimicrobial activity of Bacillus probiotics. In: Bacterial spore formers-probiotics and emerging applications. Norfolk: Horizon Bioscience; 2004. p. 171-182

53. Teng D, Gao M, Yang Y, Liu B, Tian Z, Wang J. Bio-modification of soybean meal with Bacillus subtilis or Aspergillus oryzae. Biocatal Agric Biotechnol. 2012:1:32-8. 
54. Ekwealor IA, Ebele OA. Preliminary study of $L_{L}$-lysine production by Bacillus species using various agricultural by-products. Food Nahrung. 2003;47:226-7.

55. Wei Q-K, Chen T-R, Chen J-T. Using of Lactobacillus and Bifidobacterium to product the isoflavone aglycones in fermented soymilk. Int J Food Microbiol. 2007;117:120-4.

56. Lin F-M, Chiu C-H, Pan T-M. Fermentation of a milk-soymilk and Lycium chinense Miller mixture using a new isolate of Lactobacillus paracasei subsp. paracasei NTU101 and Bifidobacterium longum. J Ind Microbiol Biotechnol. 2004;31:559-64.

57. Lee $\mathrm{S}$, Jang D-H, Choi HJ, Park Y-S. Optimization of soymilk fermentation by the protease-producing Lactobacillus paracasei. Korean J Food Sci Technol. 2013:45:571-7.

58. Chuang L-C, Huang C-S, Ou-Yang L-W, Lin S-Y. Probiotic Lactobacillus paracasei effect on cariogenic bacterial flora. Clin Oral Investig. 2011;15:471-6.

59. Chiang S-S, Pan T-M. Beneficial effects of Lactobacillus paracasei subsp. paracasei NTU 101 and its fermented products. Appl Microbiol Biotechnol. 2012;93:903-16.

60. Song Y-S, Frías J, Martinez-Villaluenga C, Vidal-Valdeverde C, de Mejia EG. Immunoreactivity reduction of soybean meal by fermentation, effect on amino acid composition and antigenicity of commercial soy products. Food Chem. 2008;108:571-81.

61. Ouoba LII, Diawara B, Christensen T, Mikkelsen JD, Jakobsen M. Degradation of polysaccharides and non-digestible oligosaccharides by Bacillus subtilis and Bacillus pumilus isolated from Soumbala, a fermented African locust bean (Parkia biglobosa) food Condiment. Eur Food Res Technol. 2007;224:689-94.

62. Aderibigbe EY, Odunfa S. Growth and extracellular enzyme production by strains of Bacillus species isolated from fermenting African locust bean, iru. J Appl Microbiol. 1990;69:662-71

63. Chen T, Wei Q, Chi Z. Effect of oligosaccharides and isoflavones aglycones in defatted soy meal fermented by Lactobacillus paracasei and Bifidobacterium longum. Afr J Microbiol Res. 2011;5:2011-8.

64. Giraud E, Brauman A, Keleke S, Lelong B, Raimbault M. Isolation and physiological study of an amylolytic strain of Lactobacillus plantarum. Appl Microbiol Biotechnol. 1991;36:379-83.

65. Morlon-Guyot J, Guyot J, Pot B, De Haut IJ, Raimbault M. Lactobacillus manihotivorans sp. nov., a new starch-hydrolysing lactic acid bacterium isolated during cassava sour starch fermentation. Int J Syst Evol Microbiol. 1998;48:1101-9.

66. Sanni A, Morlon-Guyot J, Guyot J. New efficient amylase-producing strains of Lactobacillus plantarum and L. fermentum isolated from different Nigerian traditional fermented foods. Int J Food Microbiol. 2002;72:53-62.

67. Zotta T, Parente E, Ricciardi A. Aerobic metabolism in the genus Lactobacillus: impact on stress response and potential applications in the food industry. J Appl Microbiol. 2017;122:857-69.

68. Hugenholtz J. Citrate metabolism in lactic acid bacteria. FEMS Microbiol Rev. 1993;12:165-78.

69. LV Y-C, Song H-L, Li X, Wu L, Guo S-T. Influence of blanching and grinding process with hot water on beany and non-beany flavor in soymilk. J Food Sci. 2011;76:S20-5.

70. Bott L, Chambers E IV. Sensory characteristics of combinations of chemicals potentially associated with beany aroma in foods. J Sens Stud. 2006;21:308-21.

71. Blagden TD, Gilliland SE. Reduction of levels of volatile components associated with the "beany" flavor in soymilk by lactobacilli and streptococci. J Food Sci. 2005;70:M186-9.

72. Chua J-Y, Lu Y, Liu S-Q. Biotransformation of soy whey into soy alcoholic beverage by four commercial strains of Saccharomyces cerevisiae. Int J Food Microbiol. 2017;262:14-22.

73. Wittmann C, Hans M, Bluemke W. Metabolic physiology of aromaproducing Kluyveromyces marxianus. Yeast. 2002;19:1351-63.

74. Ayseli MT, Ayseli YI. Flavors of the future: Health benefits of flavor precursors and volatile compounds in plant foods. Trends Food Sci Technol. 2016;48:69-77.

75. Hubert J, Berger M, Nepveu F, Paul F, Daydé J. Effects of fermentation on the phytochemical composition and antioxidant properties of soy germ. Food Chem. 2008;109:709-21.
76. Xu M, Jin Z, Lan Y, Rao J, Chen B. HS-SPME-GC-MS/olfactometry combined with chemometrics to assess the impact of germination on flavor attributes of chickpea, lentil, and yellow pea flours. Food Chem. 2019;280:83-95.

77. Vong WC, Liu SQ. Changes in volatile profile of soybean residue (okara) upon solid-state fermentation by yeasts. J Sci Food Agric. 2017;97:135-43.

78. Schindler S, Zelena K, Krings U, Bez J, Eisner P, Berger RG. Improvement of the aroma of pea (Pisum sativum) protein extracts by lactic acid fermentation. Food Biotechnol. 2012;26:58-74.

79. Schwechheimer SK, Becker J, Wittmann C. Towards better understanding of industrial cell factories: novel approaches for ${ }^{13} \mathrm{C}$ metabolic flux analysis in complex nutrient environments. Curr Opin Biotechnol. 2018;54:128-37.

80. Schwechheimer SK, Becker J, Peyriga L, Portais J-C, Wittmann C. Metabolic flux analysis in Ashbya gossypii using ${ }^{13} \mathrm{C}$-labeled yeast extract: industrial riboflavin production under complex nutrient conditions. Microb Cell Fact. 2018;17:162.

81. Kohlstedt M, Sappa PK, Meyer H, Maaß S, Zaprasis A, Hoffmann T, Becker J, Steil L, Hecker M, van Dijl JM. Adaptation of Bacillus subtilis carbon core metabolism to simultaneous nutrient limitation and osmotic challenge: a multi-omics perspective. Environ Microbiol. 2014;16:1898-917.

82. Wittmann C, Kim HM, Heinzle E. Metabolic network analysis of lysine producing Corynebacterium glutamicum at a miniaturized scale. Biotechnol Bioeng. 2004;87:1-6.

83. Gangoiti J, van Leeuwen SS, Meng X, Duboux S, Vafiadi C, Pijning T, Dijkhuizen L. Mining novel starch-converting Glycoside Hydrolase 70 enzymes from the Nestlé Culture Collection genome database: the Lactobacillus reuteri NCC 2613 GtfB. Sci Rep. 2017;7:1-16.

84. Marchler-Bauer A, Anderson JB, DeWeese-Scott C, Fedorova ND, Geer LY, He S, Hurwitz DI, Jackson JD, Jacobs AR, Lanczycki CJ. CDD: a curated Entrez database of conserved domain alignments. Nucleic Acids Res. 2003:31:383-7.

85. De Man J, Rogosa M, Sharpe ME. A medium for the cultivation of lactobacilli. J Appl Bacteriol. 1960:23:130-5.

86. Vogel RF, Böcker G, Stolz P, Ehrmann M, Fanta D, Ludwig W, Pot B, Kersters K, Schleifer KH, Hammes WP. Identification of lactobacilli from sourdough and description of Lactobacillus pontis sp. nov. Int J Syst Evol Microbiol. 1994;44:223-9.

87. Wittmann C, Kim HM, John G, Heinzle E. Characterization and application of an optical sensor for quantification of dissolved $\mathrm{O}_{2}$ in shakeflasks. Biotechnol Lett. 2003;25:377-80.

88. Thomas P, Sekhar AC, Upreti R, Mujawar MM, Pasha SS. Optimization of single plate-serial dilution spotting (SP-SDS) with sample anchoring as an assured method for bacterial and yeast cfu enumeration and single colony isolation from diverse samples. Biotechnol Rep. 2015;8:45-55.

89. Krömer JO, Fritz M, Heinzle E, Wittmann C. In vivo quantification of intracellular amino acids and intermediates of the methionine pathway in Corynebacterium glutamicum. Anal Biochem. 2005;340:171-3.

90. Wittmann C. Fluxome analysis using GC-MS. Microb Cell Fact. 2007;6:6.

91. Lange A, Becker J, Schulze D, Cahoreau E, Portais J-C, Haefner S, Schröder H, Krawczyk J, Zelder O, Wittmann C. Bio-based succinate from sucrose: high-resolution ${ }^{13} \mathrm{C}$ metabolic flux analysis and metabolic engineering of the rumen bacterium Basfia succiniciproducens. Metab Eng. 2017:44:198-212.

92. Caprioli G, Giusti F, Ballini R, Sagratini G, Vila-Donat P, Vittori S, Fiorini D. Lipid nutritional value of legumes: Evaluation of different extraction methods and determination of fatty acid composition. Food Chem. 2016;192:965-71

93. van Winden WA, Wittmann C, Heinzle E, Heijnen JJ. Correcting mass isotopomer distributions for naturally occurring isotopes. Biotechnol Bioeng. 2002;80:477-9.

94. Achouri A, Boye J, Zamani Y. Identification of volatile compounds in soymilk using solid-phase microextraction-gas chromatography. Food Chem. 2006;99:759-66.

95. Rezola A, de Figueiredo LF, Brock M, Pey J, Podhorski A, Wittmann C, Schuster S, Bockmayr A, Planes FJ. Exploring metabolic pathways in genome-scale networks via generating flux modes. Bioinformatics. 2011;27:534-40. 
96. Chou HT, Hegazy M, Lu C-D. L-Lysine catabolism is controlled by -arginine and ArgR in Pseudomonas aeruginosa PAO1. J Bacteriol. 2010;192:5874-80.

97. Revelles O, Espinosa-Urgel M, Fuhrer T, Sauer U, Ramos JL. Multiple and

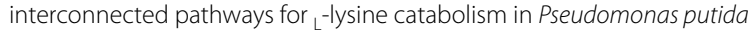
KT2440. J Bacteriol. 2005;187:7500-10.

98. Zhang Z, Yang M, Peng Q, Wang G, Zheng Q, Zhang J, Song F. Transcription of the lysine-2, 3-aminomutase gene in the kam locus of Bacillus thuringiensis subsp. Kurstaki HD73 is controlled by both $\sigma 54$ and $\sigma \mathrm{K}$ factors. J Bacteriol. 2014;196:2934-43.

99. Kaczmarska KT, Chandra-Hioe MV, Frank D, Arcot J. Aroma characteristics of lupin and soybean after germination and effect of fermentation on lupin aroma. LWT. 2018;87:225-33.

100. Li C, Li W, Chen X, Feng M, Rui X, Jiang M, Dong M. Microbiological, physicochemical and rheological properties of fermented soymilk produced with exopolysaccharide (EPS) producing lactic acid bacteria strains. LWT. 2014;57:477-85.

101. Vara-Ubol S, Chambers E, Chambers DH. Sensory characteristics of chemical compounds potentially associated with beany aroma in foods. J Sens Stud. 2004;19:15-26.

102. Boatright W, Lei Q. Compounds contributing to the "beany" odor of aqueous solutions of soy protein isolates. J Food Sci. 1999;64:667-70.

103. The Good Scents Company Information System. The Good Scents Company Information System. 2018. http://www.thegoodscentscompany. com/. Accessed 3 Mar 2021.
104. Verginer M, Leitner E, Berg G. Production of volatile metabolites by grape-associated microorganisms. J Agric Food Chem. 2010;58:8344-50

105. Sabatini N, Mucciarella MR, Marsilio V. Volatile compounds in uninoculated and inoculated table olives with Lactobacillus plantarum (Olea europaea L, cv. Moresca and Kalamata). LWT. 2008;41:2017-22.

106. Yang DS, Shewfelt RL, Lee K-S, Kays SJ. Comparison of odor-active compounds from six distinctly different rice flavor types. J Agric Food Chem. 2008:56:2780-7.

107. Zeng Z, Zhang H, Chen JY, Zhang T, Matsunaga R. Flavor volatiles of rice during cooking analyzed by modified headspace SPME/GC-MS. Cereal Chem. 2008;85:140-5.

108. Sell C. On the unpredictability of odor. Angew Chem Int Ed. 2006:45:6254-61.

109. CAMEO Chemicals. National Oceanic and Atmospheric Administration's Office of Response and Restoration in Partnership with the Environmental Protection Agency's Office of Emergency Management and the U.S. Coast Guard's Research and Development, Washington D.C. 2015 https://pubchem.ncbi.nlm.nih.gov/. Accessed 3 Mar 2021.

\section{Publisher's Note}

Springer Nature remains neutral with regard to jurisdictional claims in published maps and institutional affiliations.
Ready to submit your research? Choose BMC and benefit from:

- fast, convenient online submission

- thorough peer review by experienced researchers in your field

- rapid publication on acceptance

- support for research data, including large and complex data types

- gold Open Access which fosters wider collaboration and increased citations

- maximum visibility for your research: over $100 \mathrm{M}$ website views per year

At BMC, research is always in progress.

Learn more biomedcentral.com/submissions 